\title{
Tie1 attenuation reduces murine atherosclerosis in a dose-dependent and shear stress-specific manner
}

\author{
Kel Vin Woo, ${ }^{1,2}$ Xianghu Qu, ${ }^{1}$ Vladimir R. Babaev, ${ }^{3}$ MacRae F. Linton, 3,4 \\ Raul J. Guzman,2,5 Sergio Fazio,3,6 and H. Scott Baldwin',2 \\ 1Department of Pediatrics, Division of Cardiology, ${ }^{2}$ Department of Cell and Developmental Biology, ${ }^{3}$ Department of Medicine, \\ ${ }^{4}$ Department of Pharmacology, ${ }^{5}$ Department of Vascular Surgery, Section of Surgical Sciences, and \\ ${ }^{6}$ Department of Pathology, Vanderbilt University School of Medicine, Nashville, Tennessee, USA.
}

\begin{abstract}
Although the response of endothelial cells to the disturbed blood flow in the vicinity of atherosclerotic lesions is known to be distinct from that elicited by nonatherogenic laminar flow, the mechanisms involved are poorly understood. Our initial studies confirmed that expression of the endothelial receptor tyrosine kinase Tie1 was evident at regions of atherogenic flow in mature animals. We therefore hypothesized that Tie1 plays a role in the endothelial response to atherogenic shear stress. Consistent with this, we found that $\mathrm{Tie} \mathrm{1}^{+/-}$mice bred to the apoE-deficient background displayed a $35 \%$ reduction in atherosclerosis relative to $\mathrm{Tie}^{+/+} ; \mathrm{Apoe}^{-/-}$mice. Since deletion of Tie1 results in embryonic lethality secondary to vascular dysfunction, we used conditional and inducible mutagenesis to study the effect of endothelial-specific Tie 1 attenuation on atherogenesis in $\mathrm{Apoe}^{-/-}$mice and found a dose-dependent decrease in atherosclerotic lesions. Analysis of primary aortic endothelial cells indicated that atheroprotective laminar flow decreased Tie1 expression in vitro. Attenuation of Tie1 was associated with an increase in eNOS expression and Tie2 phosphorylation. In addition, Tie1 attenuation increased IkB $\alpha$ expression while decreasing ICAM levels. In summary, we have found that shear stress conditions that modulate atherogenic events also regulate Tie1 expression. Therefore, Tie1 may play a novel proinflammatory role in atherosclerosis.
\end{abstract}

\section{Introduction}

Atherosclerotic lesions have a predilection for locales exposed to disturbed blood flow that can trigger inflammation and apoptosis (1-5). Disturbed flow is seen at the aortic sinus and at branch points such as bifurcations of the carotid, coronary, and renal arteries (2). In contrast, lesions rarely form along nonbranching segments of the descending aorta, where laminar flow is predominant and endothelial cells are protected against inflammatory activation and apoptosis $(6,7)$, and show increased expression of SOD and eNOS (8).

The force exerted by blood flow on the endothelium is termed shear stress. Mechanosensors of shear stress in endothelial cells include integrins, $\mathrm{G}$ protein-coupled receptors, PECAM-1, and the membrane lipid layer (5). The most recent additions to the list of shear stress mediators are the members of the Tie family of receptor tyrosine kinases $(9,10)$. A tyrosine kinase with immunoglobulin-like and EGF-like domains 1, Tie1 is expressed almost exclusively in endothelial cells (11). Ablation of Tie1 expression results in early embryonic lethality after day 13.5 as a result of severe edema, hemorrhage, and loss of microvessel integrity $(12,13)$. Puri et al. (12) and Sato et al. (13) have independently shown that Tie 1 is not essential for vasculogenesis but is required during embryonic development for the integrity and survival of vascular endothelial cells. Although Tie1 is important for embryonic vessel development, its expression is also increased during pathologic conditions in the adult (14-16). Recent studies have indicated expression of Tie 1 in inflammatory tissue of rheumatoid arthritis and osteoarthritis patients $(17,18)$. Additionally, overexpression

Conflict of interest: The authors have declared that no conflict of interest exists. Citation for this article: J Clin Invest. 2011;121(4):1624-1635. doi:10.1172/JCI42040. of Tie1 augmented the inflammatory markers VCAM-1, ICAM-1, and E-selectin (19). Conversely, analyses of Tie1 siRNA-transfected HUVECs showed a decrease in the levels of inflammatory markers, including TLR 2 and IL-1 $\beta$. These data suggest that Tie 1 expression mediates proinflammatory responses in endothelial cells.

Tie 1 expression in the adult correlates distinctively to vascular regions exposed to disturbed flow in both physiological and pathological conditions. In optic microvessels, Tie1 promoter activity is increased at bifurcations and downstream of branches (9). The effect of fluid shear on Tie1 has also been demonstrated in vitro, whereby expression is decreased with brief application of laminar flow and altered by acute changes in shear stress magnitude (10). Conversely, disturbed flow in vitro upregulates Tie 1 promoter activity (9). Tie 1 is commonly found associated with Tie2 (20-22). Overexpression of Tie 1 with Tie 2 results in a cooperative recruitment of both receptors to the cell border (23). Tie1 can be activated by an Ang1 chimeric protein (COMP-Ang1) as well as by native Ang1 and Ang4, but not by Ang2 or Ang3 (21). Notably, coexpression with Tie2 was required for Tie1 activation (21), and association of Tie 1 with Tie 2 has been reported to modulate Tie 2 activation $(22,24,25)$. In bovine aortic endothelial cells subjected to shear stress in vitro (10), Tie1 was cleaved, and the intracellular product was found to coimmunoprecipitate with the protein tyrosine phosphatase Shp2 (26), which indicates that Tie1 might transduce signals in the absence of ligand activation. To our knowledge, the role of Tie 1 in shear stress-induced vascular diseases such as atherosclerosis has not previously been studied.

We hypothesized that Tie 1 plays an important role in shear stressinduced atherosclerosis and that attenuation of Tie 1 would ameliorate atherosclerotic burden. In the present study, we show that Tie1 


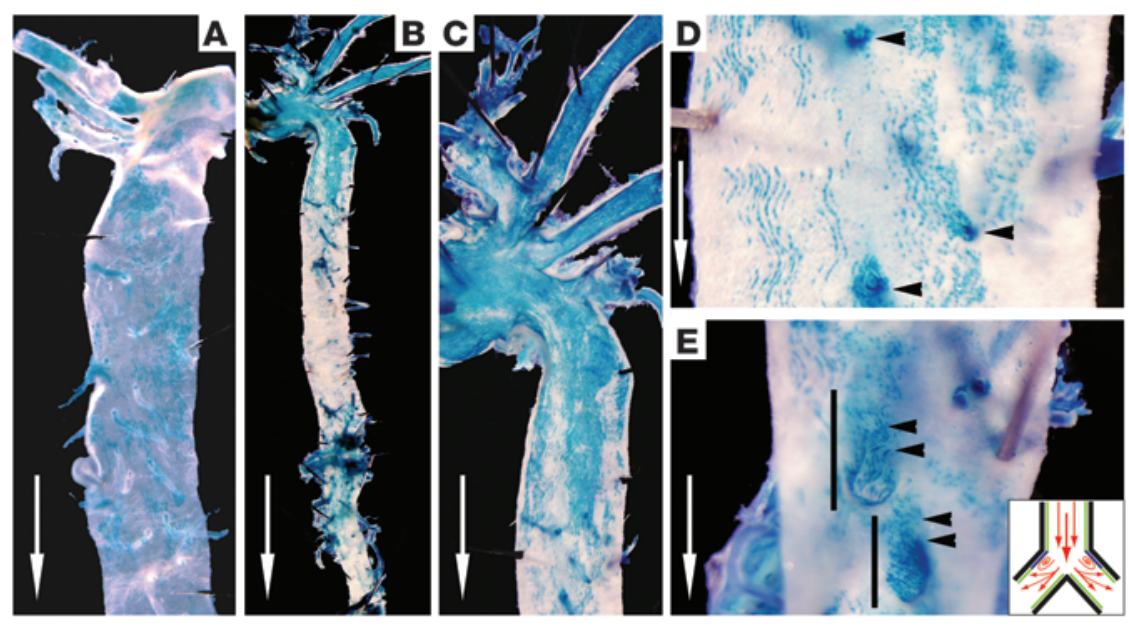

Figure 1

Tie1 expression at shear stress-specific sites in the adult aorta. Representative en face X-galstained, whole-mount distal aorta of 4-week-old (A) and 12-week-old (B-E) Tie1-LacZ mice. (A) Pervasive endothelial Tie1-LacZ expression in the aortic arch, branch arteries, and descending aorta wall of immature 4-week-old mouse. (B) Low-magnification view of aorta (aortic arch and thoracic and abdominal aorta) and (C) higher-magnification view depicting endothelial Tie1-LacZ expression in the aortic arch diminishing in the thoracic aorta as laminar flow is restored. (D) High-magnification image of thoracic aorta wall, illustrating endothelial Tie1-LacZ expression at ostia of vertebral artery branches (arrowheads). (E) High-magnification image of abdominal aorta wall, showing distinct X-gal staining at the outer walls of renal artery bifurcations (arrowheads). Inset: illustration of proatherogenic, disturbed flow as experienced at aortic branch points. White arrows indicate direction of blood flow. Original magnification, $\times 10(B) ; \times 20(\mathbf{A}$ and $\mathbf{C}) ; \times 40(\mathbf{D}$ and $\mathbf{E})$.

expression was induced in atherosclerosis-prone regions of the vasculature, characterized by disturbed flow. Moreover, we show that increasing shear stress under laminar flow conditions downregulated Tie1 promoter activity in vivo. We also report a dose-dependent reduction in atherosclerosis in Tie1-attenuated Apoe $^{-/-}$mice. Furthermore, we devised what we believe to be a novel method of isolating murine aortic endothelial cells (MAECs), facilitating in vitro experiments in parallel with our in vivo model. In vitro laminar flow with high shear stress for 24 hours downregulated Tie 1 levels. Additionally, these in vitro studies document that Tie1 deletion increased shear stress-mediated eNOS and Tie2 phosphorylation, while increasing $\mathrm{IkB} \alpha$ and decreasing ICAM levels. Our findings suggest that Tie 1 may be a key modulator of endothelial response to pathological shear stress and a novel target of therapy for atherosclerosis.

\section{Results}

Tie1 is expressed at regions of atherogenic disturbed flow. Previous studies have shown that Tie 1 is ubiquitously expressed in various endothelia at birth, including those of heart, lungs, kidney, liver, and brain (27). To map the expression pattern of Tie 1 in adult macrovasculature, we used a transgenic mouse with Tie 1 promoter-driven LacZ expression (12). In this model, the LacZ gene is knocked into the Tie1 locus (Tie $1^{l z /+}$ ) and placed under the control of endogenous Tie 1 regulatory elements. As expected, Tie1-LacZ activity was ubiquitously expressed throughout the aorta and its branches in 4-week-old animals (Figure 1A), consistent with the role of an activated endothelium. Interestingly, in the 12-week-old adult mouse aorta, this expression was attenuated in the descending aorta (thoracic and abdominal segments). Whereas expres-
Figure 1, C and D) as seen in nonatherosclerotic littermates. This expression pattern persisted in 24-week-old Tie $1^{l z /+} ; A p o e^{-/-}$mice with advanced atherosclerotic plaque burden (Supplemental Figure 1, E and F). These results confirmed the persistence of accentuated Tie 1 expression in regions characterized by disturbed flow.

In vivo Tie1 expression is reduced by laminar flow with increased shear stress. To study whether shear stress modification in vivo would affect Tie 1 expression, we used shear stress-modifying casts (Figure 2, A and B). We implanted casts around the right common carotid artery of Tie1-LacZ mice for 7 days. These casts modulate endogenous shear stress by inducing lowered shear stress immediately upstream, increased shear stress inside the cast, and oscillatory shear stress with vortex flow immediately downstream $(30,31)$. Cheng et al. previously described increased eNOS activity in the tapered region of the cast, where laminar flow with increased shear stress is found (30), and documented formation of atherosclerotic lesions in the adjacent upstream region experiencing laminar flow with low shear stress and in the immediate downstream area undergoing oscillatory flow (31). Right common carotid arteries implanted with control nontapered casts $(n=4)$ expressed LacZ uniformly along the vessel (Figure 2D), similar to nonimplanted left subclavian and left carotid arteries. In contrast, X-gal staining was attenuated in the tapered region of the cast, where laminar flow with increased shear stress is induced ( $n=4$; Figure 2C). Comparable to controls, LacZ activity persisted in the aforementioned regions adjacent to the cast. Persistent endothelial expression of VE-cadherin in the areas of increased shear stress confirmed that the attenuation of Tie1-LacZ activity was not the result of endothelial denudation (Supplemental Figure 2), as also previously documented by others 

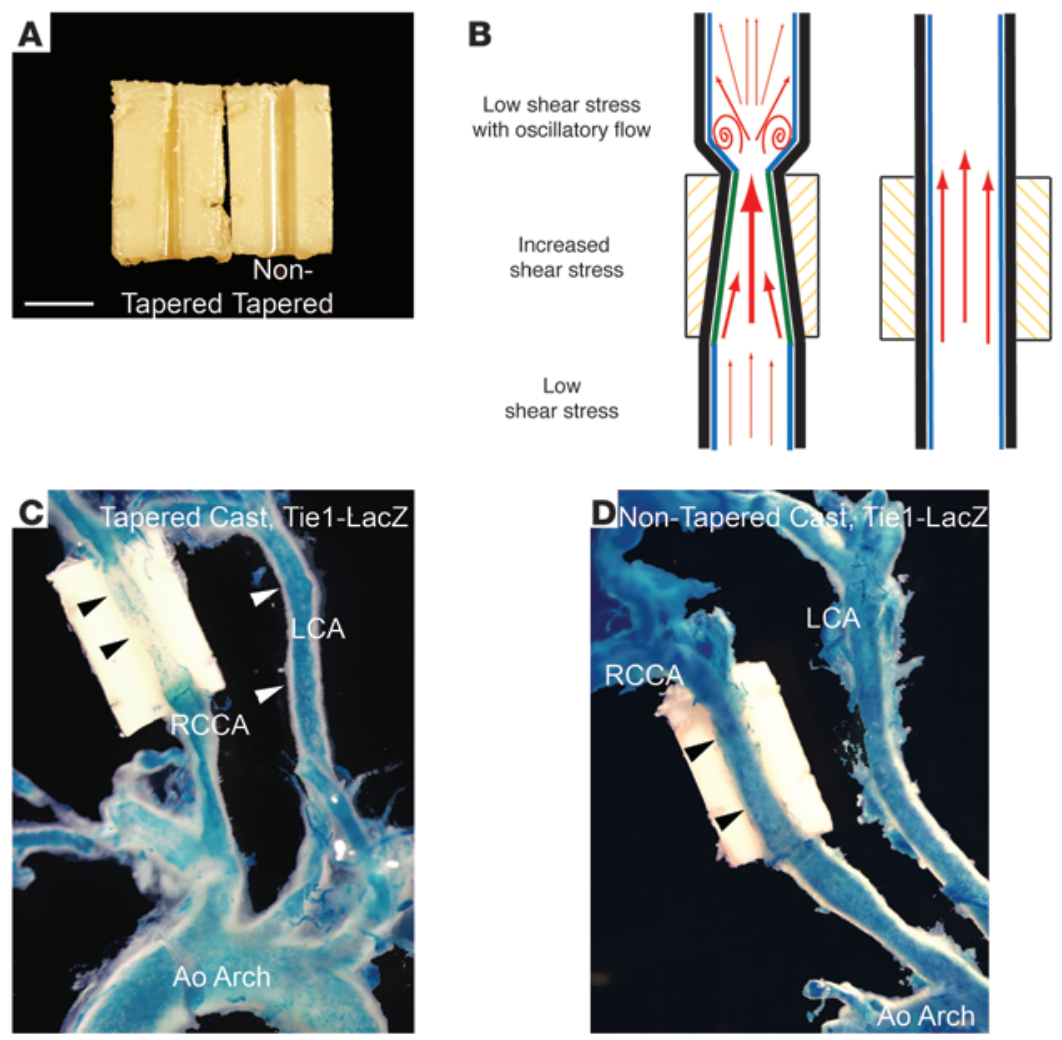

\section{Figure 2}

Tie1 promoter activity is downregulated by laminar flow with increased shear stress. (A) Tapered and nontapered control casts that were surgically implanted in mouse carotid arteries. Scale bar: $1 \mathrm{~mm}$. (B) Illustration of tapered casts manipulating in vivo shear stress, inducing lowered shear stress upstream, increased shear stress inside, and oscillatory flow with shear stress immediately downstream of the cast. Control nontapered casts do not interfere with in vivo shear stress. (C and D) Representative whole-mount X-gal-stained Tie1-LacZ mouse carotid arteries with shear stress-modifying casts 7 days after implantation. (C) Tapered cast showed diminished X-gal staining along the region of increased shear stress inside the cast. (D) Control nontapered casts demonstrated persistent uniform X-gal staining. RCCA, right common carotid artery; LCA, left carotid artery; Ao arch, aortic arch. Original magnification, $\times 50$.
$(29,31)$. These results suggest that Tie 1 expression is attenuated by conditions of increased endogenous shear stress with laminar flow. Furthermore, these results are suggestive of dynamic repression of Tie1 promoter activity in the short term (7 days).

Tie1 suppression reduces distal aorta atherosclerosis progression in Apoe-null mice. To determine the role of Tie 1 in atherosclerosis, Tie $1^{+/-} ; \mathrm{Apoe}^{-/}$ female mice $(n=49)$ fed a regular chow diet were evaluated for atherosclerotic plaque burden and compared with control Tie ${ }^{+/+} ; \mathrm{Apoe}^{-/-}$ female littermates $(n=41)$. Female mice were chosen because of a clear gender-dependent difference in the progression of atherosclerosis (32). Mice were assessed at early (12 weeks old), intermediate (18 weeks old), and advanced (24 and 49 weeks old) stages of atherosclerosis. There were no statistically significant differences in serum cholesterol and triglyceride levels between experimental and control mice (Table 1). Semiquantitative RT-PCR analysis of descending aorta confirmed a 49\% decrease in Tie1 mRNA expression of Tie $1^{+/-}$mice (Figure 3A). Western blot assay of pulmonary endothelia showed a $40 \%$ reduction in Tie 1 protein expression throughout the vascular endothelium (Figure 3B).

In the atherosclerosis-prone, disturbed-flow regions of the aorta, en face analysis showed $37.9 \%$ suppression of atherosclerotic lesions in 24-week-old mice (Tie ${ }^{+/+}$; Apoe $^{-/-}, 1.69 \% \pm 0.24 \%$; Tie $1^{+-} ;$Apoe $^{-/-}, 1.04 \% \pm 0.20 \%, P<0.05$; Figure 3D). This difference persisted for 6 months (i.e., 49 weeks of age), when the area covered by lesions was $16.13 \% \pm 2.80 \%$ in $\mathrm{Tie}^{\mathrm{I}^{++}}$; Apoe $^{-/-}$and $10.57 \% \pm 1.49 \%$ in Tie $1^{+-}$; Apoe $^{-/-}$mice (34.4\% reduction, $P<0.05$; Figure 3, C and D). Interestingly, no statistically significant differences were found in the early and intermediate disease stage groups, although trends were confirmatory of what was seen at later disease stages (12 weeks, $0.61 \% \pm 0.14 \%$ vs. $0.49 \% \pm 0.05 \%, P=$ NS; 18 weeks, $1.52 \% \pm 0.84 \%$ vs. $0.55 \% \pm 0.05 \%, P=\mathrm{NS}$; Figure $3 \mathrm{D})$.
In the aortic sinus, we found no statistically significant differences in the extent of lesion area between Tie $1^{+/+} ; A$ poe ${ }^{-/-}$and Tie $1^{+/-} ;$Apoe $^{-/-}$mice at any stage (12 weeks, 40,030 $\pm 15,311 \mathrm{vs.}$ $51,719 \pm 6,094 \mu \mathrm{m}^{2}$; 18 weeks, $156,155 \pm 40,275$ vs. $152,210 \pm$ $25,157 \mu \mathrm{m}^{2}$; 24 weeks, $286,433 \pm 16,160$ vs. $334,760 \pm 41,861 \mu \mathrm{m}^{2}$; 49 weeks, 426,680 $\pm 40,877$ vs. 529,025 $\pm 52,711 \mu \mathrm{m}^{2}$; Supplemental Figure 3A). The trend toward increased lesions in Tie $1^{+/}$; Apoe ${ }^{-/-}$mice, the opposite of the effects seen in the distal aorta, is interesting but does not warrant further comment, given the lack of statistical significance.

Endothelial-specific Tie1 deficiency alleviates atherosclerosis progression in a dose-dependent manner. We next assessed the effect of endothelialspecific Tie1 deletion on development of atherosclerotic lesions in Apoe $^{-/-}$mice. Since Tie1 deletion leads to early embryonic lethality $(12,13)$, we used Cre-Lox technology to delete Tie1 in a spatially and temporally defined manner. We used SCL-ERT-Cre mice to achieve endothelial-specific, tamoxifen-mediated induction of Cre expression (33). To determine an efficient tamoxifen induction dosage, $S C L-E R^{T}$-Cre mice were bred to Rosa-LacZ reporter background. Using a protocol of $2 \mathrm{mg}$ intraperitoneal tamoxifen injection every 48 hours, for 14 days, we were able to obtain robust, endothelial-specific, Cre-mediated deletion (evidenced by X-gal staining), as documented in the aortic valve endothelium and in the microvasculature of the endocardium (Figure 4A). Tie1 $1^{-/ f}$ mice were then bred with $S C L-E R^{T}$-Cre mice, and generalized endothelialspecific deletion was quantified by Western assay of pulmonary endothelium, which showed a $81 \%$ reduction in Tie 1 protein levels (Supplemental Figure 4). In the resulting mice with a null Tie1 allele, a floxed Tie1 allele, and endothelial-specific Cre (Tie1-/fl; $S C L$ $E R^{T}$-Cre mice), tamoxifen treatment induced a $65 \%$ reduction in aortic endothelial Tie1 mRNA level (Figure 4B). 
Table 1

Plasma cholesterol and triglyceride levels for $\mathrm{Apoe}^{-/}$mice

\begin{tabular}{|c|c|c|c|}
\hline & $n$ & $\begin{array}{l}\text { Cholesterol } \\
\text { (mg/dl) }\end{array}$ & $\begin{array}{c}\text { Triglycerides } \\
\text { (mg/dl) }\end{array}$ \\
\hline \multicolumn{4}{|l|}{12 weeks old } \\
\hline Tie ${ }^{+/+} ; A p o e^{-/-}$ & 4 & 208.8 & 174.7 \\
\hline Tie $1^{-/+} ;$Apoe $^{-/-}$ & 8 & 185.8 & 153.2 \\
\hline \multicolumn{4}{|l|}{18 weeks old } \\
\hline $\mathrm{Tie}^{+/+} ; \mathrm{Apoe}^{-/-}$ & 9 & 233.5 & 101.4 \\
\hline Tie $1^{-/+} ; A^{\prime} e^{-/-}$ & 14 & 275.3 & 102.0 \\
\hline \multicolumn{4}{|l|}{24 weeks old } \\
\hline Tie ${ }^{+/+} ; A^{\prime}$ oe $^{-/-}$ & 20 & 290.1 & 115.7 \\
\hline Tie $1^{-/+} ; \mathrm{Apoe}^{-/-}$ & 18 & 316.4 & 123.9 \\
\hline \multicolumn{4}{|l|}{49 weeks old } \\
\hline $\mathrm{Tie}^{+/+} ; A p o \mathrm{e}^{-/-}$ & 7 & 254.9 & 88.2 \\
\hline $\mathrm{Tie}^{-/+} ; \mathrm{Apoe}^{-/-}$ & 9 & 300.1 & 90.0 \\
\hline
\end{tabular}

Tie1 reduction caused no discernible effect; no significant differences were found between groups.

To assess the effect of Tie 1 deletion on atherosclerosis progres-

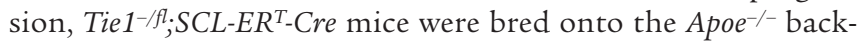

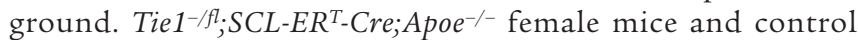
Tie $1^{f l f f} ; A_{p o e^{-/-}}$female littermates were injected with tamoxifen as described above. Because tamoxifen administration has previously been associated with attenuation of atherosclerosis after chronic and unfettered oral intake (34), we first determined whether acute and limited exposure to tamoxifen had any effect in our experimental model. We noted a protective effect ( $46 \%$ decrease) 4 weeks after treatment (i.e., 12 weeks old; $1.41 \% \pm 0.22 \%$ vs. $0.76 \% \pm 0.11 \%$, $P<0.01$; Supplemental Figure 5), which was not maintained at the 16-week time point (i.e., 24 weeks old; $4.32 \% \pm 0.54 \%$ vs. $3.64 \% \pm 0.86 \%$, $P=\mathrm{NS})$. Tamoxifen treatment temporarily decreased serum cholesterol in Tie $1^{f l f f} ;$ Apoe $^{-/-}$mice compared with untreated controls at 12 weeks of age $(456.44 \pm 40.58$ vs. $291.43 \pm 19.36 \mathrm{mg} / \mathrm{dl}$, $P<0.001)$, but this effect was lost by 24 weeks $(331.54 \pm 28.54$ vs. $345.20 \pm 24.61 \mathrm{mg} / \mathrm{dl}, P=\mathrm{NS}$; Table 2$)$. Tamoxifen treatment also reduced serum triglycerides of 12 - and 24-week-old animals (12 weeks old, $186.8 \pm 8.00$ vs. $147.98 \pm 7.38 \mathrm{mg} / \mathrm{dl}, P<0.01 ; 24$ weeks old, $200.64 \pm 9.81$ vs. $141.95 \pm 9.44 \mathrm{mg} / \mathrm{dl}, P<0.01$; Table 2$)$. However, the tamoxifen-induced reduction in serum triglycerides was not associated with an atheroprotective effect at 24 weeks.

Consistent with our previous studies, en face analysis of the aorta from Tie1-deleted animals showed a statistically significant reduction in atherosclerotic lesions. In 12-week-old mice with early disease progression, we found a $68 \%$ decrease in lesions of Tie1-deleted mice compared with controls $(0.765 \% \pm 0.114 \%$ vs. $0.244 \% \pm 0.046 \%, P<0.0005$; Figure 4D). The decrease in atherosclerosis persisted in mice up to 24 weeks of age, when Tie1 deletion resulted in a $70 \%$ decrease in plaque progression compared with controls $(3.644 \% \pm 0.865 \%$ vs. $1.108 \% \pm 0.207 \%, P<0.006$; Figure $4, \mathrm{C}$ and $\mathrm{E})$. However, similar to the atherosclerosis data in Tie1-heterozygous mice, we observed no significant difference in the degree of atherosclerosis at the aortic sinus between control Tie $1^{\text {flflfl; }}$ Apoe ${ }^{-/-}$and Tie1 ${ }^{-/ \text {flox;SCL-ERT }}$-Cre;Apoe ${ }^{-/-}$mice (12 weeks old, $16,607 \pm 5,004$ vs. 21,126 $\pm 4,274 \mu \mathrm{m}^{2} ; 24$ weeks old, $22,816 \pm 3,019$ vs. $18,587 \pm 33,856 \mu \mathrm{m}^{2}$; Supplemental Figure 3B).

Tie1 deletion had no effect on serum cholesterol levels compared with controls when both groups were treated with tamoxifen(Table 2). Serum triglycerides in Tie1-deleted mice treated with tamoxifen were slightly increased compared with tamoxifen-treated controls, but similar to those of untreated controls $(172.9,147.9$, and $186.8 \mathrm{mg} / \mathrm{dl}$, respectively; Table 2 ). These results suggest that deletion of endothelial Tie1 has a protective effect attenuating the rate of atherosclerosis progression independent of effects on serum cholesterol or triglyceride levels.

Reduction of atherosclerosis caused by Tie1 deletion may be location specific. To determine whether Tie1 deletion has an effect on atherosclerosis distribution based on location and type of shear stress, we analyzed lesions at (a) bifurcations of the aortic arch branch arteries, (b) the lesser curvature of the aortic arch, and (c) the descending thoracic and abdominal aorta. Lesion sizes at all locations were decreased as a consequence of Tie1 deletion (Figure 4, F-H), which suggests that Tie 1 plays a role in disturbed flow-mediated atherogenesis at each of these locations.

Tie 1 is not expressed in macrophages, and Tie1 reduction in vivo reduces macrophage infiltration. As shown by macrophage immunostaining, we found a $56 \%$ reduction of macrophage infiltration in Tie $1^{+/}$; Apoe $e^{-/-}$compared with control Tie $1^{+/+} ;$Apoe ${ }^{-/-}$mice $(0.33 \pm 0.03$ vs. $0.07 \pm 0.44 \mathrm{U}, n=3, P<0.01$; Supplemental Figure 6A), consistent with a decrease in inflammation associated with the attenuation in atherosclerosis. Similarly, analyses of tamoxifen-treated

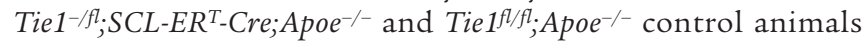
revealed a $70 \%$ reduction in macrophage infiltration $(0.46 \pm 0.07$ vs. $0.14 \pm 0.03 \mathrm{U}, n=3, P<0.05$; Supplemental Figure $6 \mathrm{~B})$. To determine whether Tie1 deletion within macrophage populations contributes to the attenuation in atherosclerosis, we evaluated the expression of Tie 1 in primary macrophages. RT-PCR analysis demonstrated that there was no detectable Tie1 mRNA in macrophages (Supplemental Figure 6C); thus, a cell-autonomous effect of Tie 1 in the macrophage population is unlikely to contribute to the decreased inflammation observed.

Tie1 attenuation in vivo reduces expression of Rho-associated, coiled-coil containing protein kinases (ROCK1 and ROCK2) and cell adbesion molecules and increases eNOS levels. To elucidate the effect of Tie1 deletion on inflammatory biomarker expression in vivo, we assayed RNA from the descending thoracic and abdominal aorta of tamoxifen-treated Tie $1^{-f l}$;SCL-ER ${ }^{T}$-Cre mice and control Tie $1^{f l / f l}$ mice. mRNA levels of ROCK1 and ROCK2 were attenuated by $70 \%$ and $52 \%$, respectively, whereas eNOS mRNA was increased (Figure 5, B-D). ICAM and VCAM mRNA expression were also decreased by $55 \%$ and $87 \%$, respectively (Figure 5, E and F).

Tie1 deletion in vitro angments shear stress-induced eNOS expression and reduces proinflammatory signaling. To determine the effect of Tie 1 deletion on endothelial cell response to altered shear stress in vitro, we developed an immortalized MAEC line from both wild-type and Tie $1^{f l f l}$; SCL-ER $R^{T}$-Cre mice. Conditionally immortalized cells were derived from the $\mathrm{H}-2 \mathrm{~K}^{\mathrm{b}}$-tsA58 transgenic mouse. Expression of the inducible tsA58 tumor $\mathrm{Ag}$ (TAg) allows for the extended propagation of MAECs under permissive conditions. At passage 10, fluorescenceactivated cell sorting analysis showed $89.7 \%$ positive immunostaining for CD31 (Supplemental Figure 7A). PECAM immunostaining showed uniform cytoplasmic distribution and increased localization to the cell border in apposition with adjacent cells (Supplemental Figure 7B). We also documented that MAECs took up 1,1'-dioctadecyl3,3,3'3'-tetramethylindocarbocyanine perchlorate-labeled acetylated LDL (DiI-AcLDL; Supplemental Figure 7C) and showed robust network formation within 24 hours in Matrigel (Supplemental Figure 7D). Our MAECs displayed cobblestone morphology (Supplemental Figure 7E) and aligned to the direction of laminar flow with high 
A

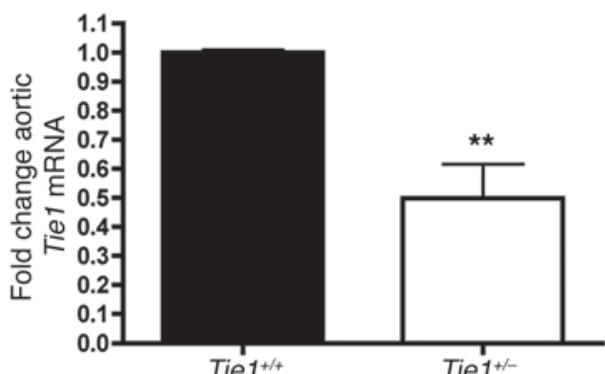

Tie ${ }^{+/+}$

49 weeks old Tie $^{+/+} ;$Apoe $^{-\alpha-}$ Tie $1^{+/-} ;$Apoe $^{-/}$

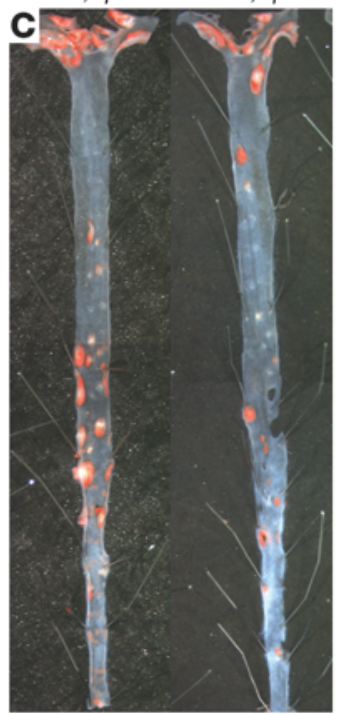

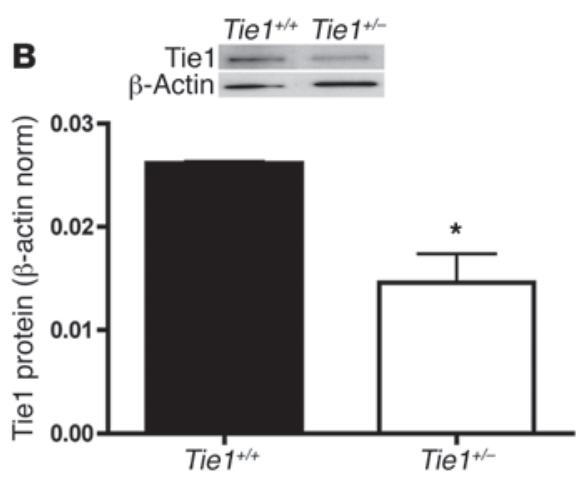

D

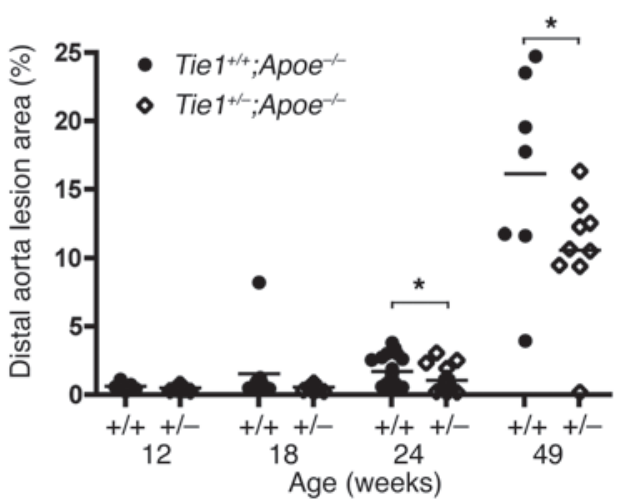

Figure 3

Tie1 heterozygosity reduces advanced-stage atherosclerosis burden. (A and B) Quantitation of Tie1 levels in $\mathrm{Tie}^{+/-}$mice of $(\mathbf{A})$ aortic endothelia by RT-PCR (49\% reduction, $P<0.01, n=4)$ and $(B)$ pulmonary tissue by Western blot (40\% suppression, $P<0.05$ ). ( $C$ and D) Effect of reduced Tie1 expression on atherosclerosis. (C) Representative images of Sudan IV-stained aorta (aortic arch and thoracic and abdominal aorta) from 49-week-old

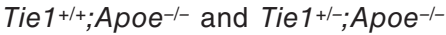
mice. (D) Atherosclerotic lesion area in $\mathrm{Tie}^{+/+} ; \mathrm{Apoe}^{-/-}$versus $\mathrm{Tie}$ 1+/; $^{+/}$ $A_{p o e^{-/}}$mice at 12, 18, 24, and 49 weeks of age. Data points denote individual animals; horizontal bars indicate group average. ${ }^{*} P<0.05$; ${ }^{* *} P<0.01$. shear stress after 24 hours (Supplemental Figure 7F). These results demonstrated that MAECs isolated from immorto mice display the same characteristics of many primary endothelial cell lines.

Next, we isolated endothelial cells from homozygous Tie $1^{f / f l} ; S C L$ $E R^{T}$-Cre immorto mice, allowing for the use of 4-hydroxytamoxifen (4OHT), the active metabolite of tamoxifen, to initiate Cre transcription and hence induce Tie 1 deletion. To ascertain activation of Cre in vitro, we immunostained $4 \mathrm{OHT}$-treated Tie $1^{f l f f} ; S C L-E R^{T}$-Cre MAECs using Cre antibody. Increased nuclear staining indicates successful translocation of Cre (Figure 6, A and B). RT-PCR and Western blot analyses of full-length Tie 1 indicate $4 \mathrm{OHT}$ administration resulted in $41 \%$ and $45 \%$ reductions, respectively, of Tie 1 expression (Figure 6, C and D). Additionally, the cleaved Tie1 intracellular fragment $(26,35,36)$ was reduced by $72 \%$ (Figure $6 \mathrm{E}$ ).

We then exposed our MAECs to high-shear stress laminar flow for 24 hours. In our MAECs, laminar flow at 20 dynes $/ \mathrm{cm}^{2}$ decreased Tie 1 receptor expression by approximately $40 \%$ (Figure $6 \mathrm{~F}$ ), and oscillatory flow at 5 dynes $/ \mathrm{cm}^{2}$ increased Tie 1 expression by $30 \%$ (Supplemental Figure 8). Laminar flow also increased eNOS protein levels and potentiated eNOS phosphorylation in Tie $1^{f l / f l}$; SCL$E R^{T}$-Cre MAECs, as expected (37). Interestingly, eNOS expression and phosphorylation were further augmented by laminar flow after tamoxifen-induced deletion of Tie 1 (Figure 6, G and H). In addition, Tie 1 deletion further decreased shear stress-induced ICAM expression and increased $\mathrm{IkB} \alpha$ expression in response to laminar shear
(Figure 6, I and J). We next observed that laminar flow increased Tie2 phosphorylation (38), and this shear stress-mediated increase in phosphorylation was accentuated by deletion of Tie1 (Figure 6K). Moreover, in vitro oscillatory flow resulted in an increase in Tie1 expression (Supplemental Figure 8A), and attenuation of Tie1 under similar flow conditions increased eNOS expression and decreased p50 nuclear translocation (Supplemental Figure 8, B and C). In conclusion, these results suggest that Tie 1 expression is regulated by shear stress and that Tie1 may have a proinflammatory role in promoting the progression of atherosclerosis.

\section{Discussion}

Our present findings provide major insights into the role of Tie 1 in atherosclerosis. First, Tie1 expression was accentuated in regions of atherogenic shear stress, such as those with disturbed flow in the adult aorta. Second, there was dynamic downregulation of Tie1 expression in vitro and in vivo under conditions of laminar flow with high shear stress. Third, in conjunction with the expression of Tie1 at atherosclerosis-prone areas, we found that Tie1 reduction alleviated atherosclerosis progression in a dose-dependent manner. Finally, our in vitro and in vivo data support a proinflammatory role for Tie1.

Previous in vivo studies have focused on the role of Tie 1 in early stages of embryonic development. Here, we showed that the expression pattern of Tie 1 in the adult macrovasculature was different from that of the immature mouse. In the aorta of a young 


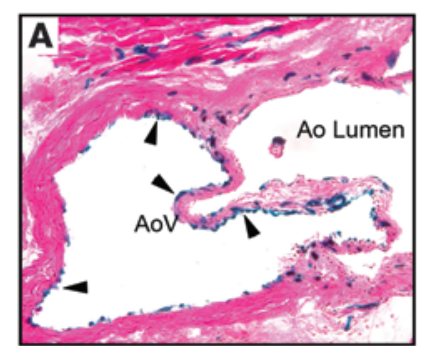

D

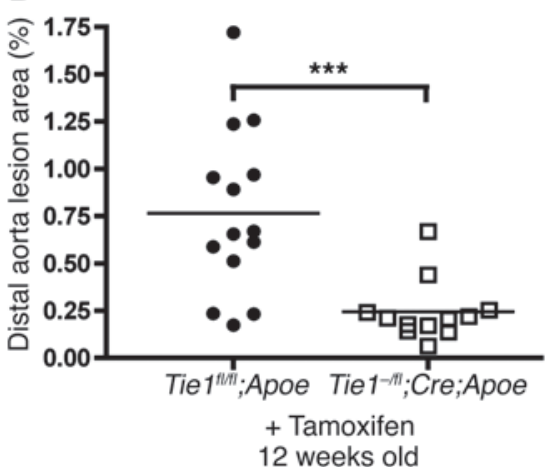

B

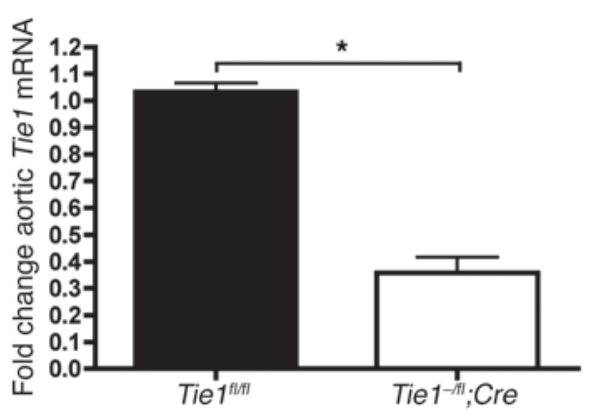

E

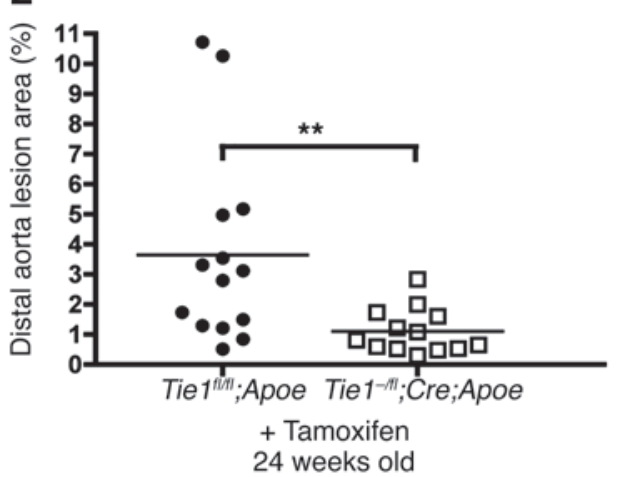

24 weeks old, + Tamoxifen
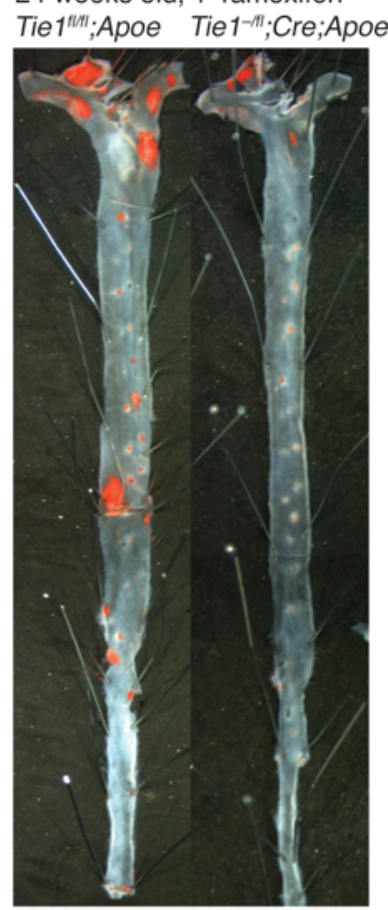

$\mathbf{F}$

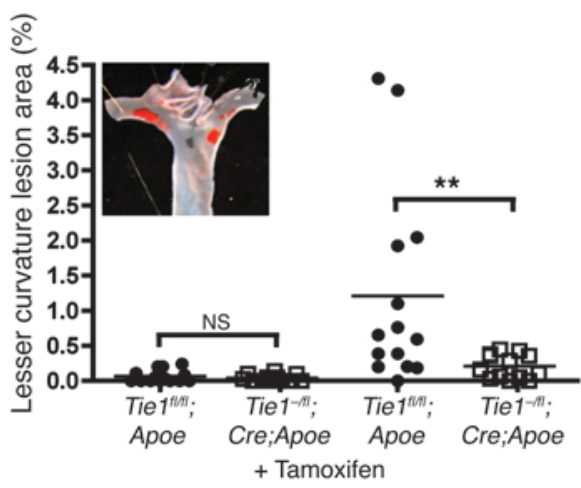

12 weeks old
G

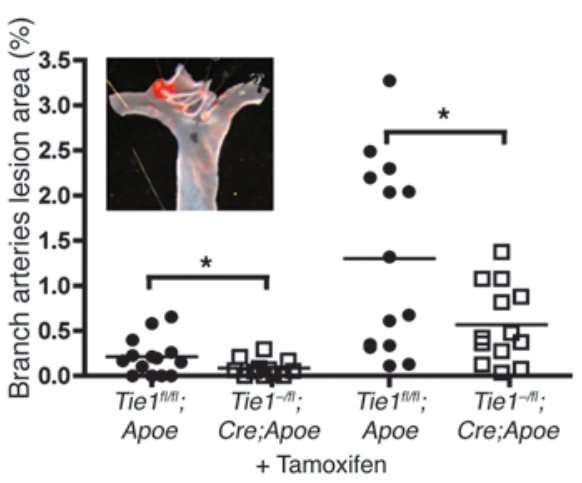

12 weeks old 24 weeks old

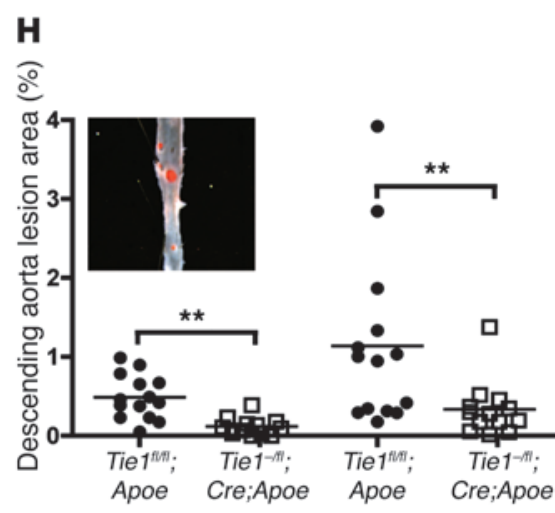

+ Tamoxifen

12 weeks old 24 weeks old

Figure 4

Endothelial-specific Tie1 deletion reduces atherosclerosis burden. (A) Representative H\&E-stained aortic valve showing endothelial-specific LacZ expression (arrowheads) from tamoxifen-treated SCL-ERT-Cre;Rosa26R-LacZ mouse. Original magnification, $\times 100$. (B) RT-PCR analysis of aortic Tie1 levels from tamoxifen-treated Tie1-lfi;SCL-ERT-Cre mice (65\% reduction, $P<0.05)$. (C) Representative Sudan IV-stained distal

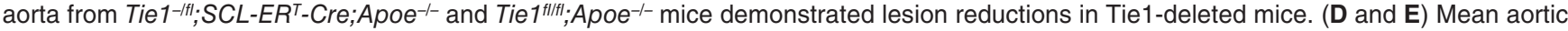

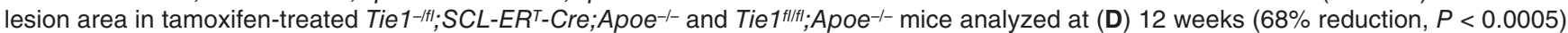
and $(\mathrm{E}) 24$ weeks $(70 \%$ reduction, $P<0.006)$. $(\mathbf{F}-\mathbf{H})$ Atherosclerotic lesion areas in Tie1-deleted mice, as assessed in 3 regions of the aorta, showed reduction of atherosclerosis in all regions of disturbed flow. Insets show respective regions of lesion analysis. Shown are mean atherosclerotic lesion areas at (F) lesser curvature of the aortic arch (12 weeks, $0.066 \% \pm 0.023 \%$ vs. $0.038 \% \pm 0.014 \%, P=\mathrm{NS} ; 24$ weeks, $1.20 \%$ $\pm 0.379 \%$ vs. $0.206 \% \pm 0.048 \%, 82 \%$ reduction, $P<0.01)$; (G) aortic arch branch arteries, including brachiocephalic, left common carotid, and left subclavian arteries ( 12 weeks, $0.211 \% \pm 0.055 \%$ vs. $0.086 \% \pm 0.026 \%, 56 \%$ reduction, $P<0.05 ; 24$ weeks, $1.29 \% \pm 0.283 \%$ vs. $0.568 \%$ $\pm 0.119 \%, 59 \%$ reduction, $P<0.05$ ); and $(\mathrm{H})$ descending aorta (12 weeks, $0.487 \% \pm 0.074 \%$ vs. $0.118 \% \pm 0.032 \%, 70 \%$ reduction, $P<0.01$; 24 weeks, $1.13 \% \pm 0.291 \%$ vs. $0.333 \% \pm 0.097 \%, 75 \%$ reduction, $P<0.01)$. Data points denote individual animals, and horizontal bars indicate group average. ${ }^{\star} P<0.05 ;{ }^{\star \star} P<0.01 ;{ }^{* \star \star} P<0.001$.

4-week-old mouse, we observed pervasive endothelial Tie 1 expression consistent with aortic immaturity. However, in the 12 -weekold adult mouse, Tie 1 expression decreased specifically in the descending aorta. We noted strong X-gal staining at locales sub- jected to atherogenic disturbed flow (39), such as the aortic arch and its branch vessels, and bifurcations of the vertebral and renal arteries. LacZ expression was also observed at the aortic sinus and the aortic valves, areas characterized by disturbed flow. 


\section{Table 2}

Plasma cholesterol and triglycerides for tamoxifen-treated $A p o e^{-/-}$mice

\begin{tabular}{|c|c|c|c|c|}
\hline Genotype & $\begin{array}{l}\text { Tamoxifen } \\
\text { treatment }\end{array}$ & $n$ & $\begin{array}{c}\text { Cholesterol } \\
\text { (mg/dl) }\end{array}$ & $\begin{array}{l}\text { Triglycerides } \\
\text { (mg/dl) }\end{array}$ \\
\hline \multicolumn{5}{|l|}{12 weeks old } \\
\hline Tie ${ }^{f|/| 1 \mid} ; S C L-E R^{T}-C r e ; A p o e^{-/-}$ & No & 5 & 456.4 & 186.8 \\
\hline Tie ${ }^{f|/|+\mid} ; A_{p o e^{-/-}}$ & Yes & 14 & $291.4^{\mathrm{A}}$ & $147.9^{\mathrm{B}}$ \\
\hline Tie1-/ft];SCL-ERT-Cre;Apoe ${ }^{-/-}$ & Yes & 12 & 293.9 & $172.9^{C}$ \\
\hline \multicolumn{5}{|l|}{24 weeks old } \\
\hline Tie $1^{f|/| t \mid} ; S C L-E R^{T}-C r e ; A p o e^{-/-}$ & No & 10 & 352.1 & 200.6 \\
\hline Tie ${ }^{f|/|+\mid} ; A_{p o e^{-/-}}$ & Yes & 17 & 345.2 & $141.9^{\mathrm{B}}$ \\
\hline 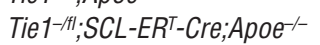 & Yes & 13 & 331.5 & $188.6^{\mathrm{C}}$ \\
\hline
\end{tabular}

Tamoxifen temporarily decreased cholesterol levels at 12 weeks (i.e., 4 weeks after treatment), but the effect was lost by 24 weeks. Tamoxifen treatment decreased triglycerides at 12 and 24 weeks. Tie 1 deletion decreased triglycerides. ${ }^{A} P<0.05$, ${ }^{\mathrm{B}} P<0.01$ vs. untreated Tie ${ }^{\text {t|lft|}} ; S C L-E R^{T}-\mathrm{Cre}$;Apoe ${ }^{-/} .{ }^{C} P<0.05$ versus tamoxifentreated Tie ${ }^{\text {H/f/H}} ; \mathrm{Apoe}^{-/}$.

The effect of altered shear stress on Tie1 expression was demonstrated in vivo by the use of vascular casts. Cheng et al. previously demonstrated that these in vivo shear stress-modifying casts altered the shear forces in the carotid arteries of Apoe-null mice (31). Lowered shear stress upstream of the cast was found to induce formation of unstable plaques, and the immediate downstream region of the cast formed stable plaques in the presence of oscillatory flow. In our Tie1-LacZ reporter mice, we found persistence of Tie 1 promoter-driven LacZ expression also in these immediate vicinities around the cast. Furthermore, Cheng and colleagues reported increased eNOS expression and detected no atherosclerotic lesions within the boundaries of the tapered cast (30). Interestingly, we found a dramatic reduction in Tie 1 promoter activity after only 7 days of implanting tapered casts in Tie1-LacZ mice. Attenuation of LacZ expression was distinctly confined to the boundaries of the tapered cast, where shear stress increases from 10 to $25 \mathrm{~N} / \mathrm{m}^{2}$. Hence, the attenuation of Tie 1 expression may be caused, at least in part, by both the higher shear stress magnitude and laminar flow conditions.

Interestingly, the in vivo response of endothelial cells to the same magnitude of shear stress may be context dependent, with endothelial cells from different vascular beds having different set points for response to shear stress. There is significant variability in the absolute wall shear stress of vascular regions within a given species, as well as between similar regions in the same species (reviewed in ref. 40). The shear stress of the mouse abdominal aorta is approximately $9 \mathrm{~N} / \mathrm{m}^{2}(41)$, and in our studies, little Tie 1 expression was detected in the regions of laminar shear, but Tie 1 expression persisted in regions of nonlaminar flow. By comparison, the average shear stress of the carotid arteries in mice has been calculated to be $15 \mathrm{~N} / \mathrm{m}^{2}$ (31), and Tie 1 was expressed in carotid endothelial cells under normal conditions. However, when shear stress in the carotid arteries was increased by placement of vascular casts to $25 \mathrm{~N} / \mathrm{m}^{2}$, a magnitude comparable to the level of shear stress produced in most in vitro studies, there was a marked attenuation in Tie 1 expression. Clearly, shear stress is not the only factor regulating Tie 1 expression, but our data suggest that expression of Tie 1 is downregulated in vitro and in vivo by shear stress profiles that are thought to be atheroprotective.
Since we found expression of Tie 1 at regions of atherogenic shear stress, and a previous study reported Tie 1 expression on both the surface and the subendothelium of atherosclerotic lesions (9), we postulated that attenuation of Tie1 may modulate atherosclerosis progression. We found that moderate reductions in Tie1 ( ie $^{+/-} ;$Apoe $^{-/-}$mice) elicited $35 \%$ and $38 \%$ reductions in atherosclerotic lesions of 24- and 49-week-old mice, respectively. Remarkably, further reductions of Tie 1 by up to $80 \%$ in Tie $1^{-/ f l}$; SCL-ER $R^{T-C r e} ; A$ poe $e^{-/-}$mice resulted in $68 \%$ and $70 \%$ reduction in lesions of 12 - and 24 -week-old mice, respectively. Hence, using 2 different mouse models, our results demonstrated that Tie 1 attenuation conferred amelioration of atherosclerosis progression.

To our knowledge, this is the first report of an in vivo biological function for Tie 1 in the adult mouse. Whereas Tie 1 plays a requisite role in prenatal vascular integrity $(12,42)$, our results suggest that loss of Tie 1 in late adult stages confers an atheroprotective effect. This divergence in function may be due in part to the complex shear stress magnitudes and flow profiles experienced pre- and postnatally. Kontos et al. previously showed that Tie 1 is capable of activating Akt to promote cell survival (43); Tie1 is also required for the maintenance of various adult vascular endothelial cell populations (12). Hence, Tie receptors may possess contextdependent roles (44) that are not only defined by endothelial heterogeneity, but also influenced by the physiologic environment that changes during vascular maturity.

We also noted that attenuation of Tie 1 did not significantly alter the extent of atherosclerotic lesions, as assessed by quantification of lipid accumulation in the aortic valve region. However, there was a clear decrease in macrophage infiltration in this region. Interestingly, Tie1 attenuation elicited a trend of increased lesions at the aortic sinus, an effect opposite to that observed in the distal aorta. Previous studies have demonstrated a predilection of lesions for specific locales of the distal aorta in PECAM-knockout mice on either the Apoe-deficient or the LDL receptor-deficient background $(45,46)$. The aortic valve also experiences a unique and complex shear stress profile not evidenced elsewhere in the vasculature. Peacock previously described the flow profile in the aortic sinus as turbulent, composed of spinning vortices superimposed with random motion of fluid particles (28). In contrast, the flow profile at aortic bifurcations distal to the aortic sinus has been described as recirculatory (4), characterized by bidirectional blood flow with the resultant effect of a low time-averaged shear stress (2). Additionally, Butcher et al. demonstrated that the shear stress-induced transcriptional response of valvular endothelial cells is vastly different from aortic endothelial cells. More than 400 genes were differentially expressed, and overall, the inflammatory response of valvular endothelial cells were found to be less pronounced than that of aortic endothelial cells (47). Hence, Tie1 may regulate atherosclerosis progression in a shear stress-specific manner, discriminating between different flow profiles characteristic of unique anatomical and physiological locations within the vascular system and further highlighting the context-dependent response of heterogeneous endothelial populations.

To further investigate the effect of shear stress on Tie 1 expression in vitro, we devised a method of isolating genetically modified MAECs that maintain a high percentage of cells displaying 
A

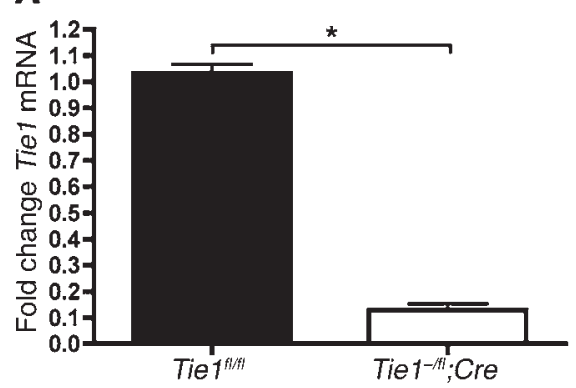

D

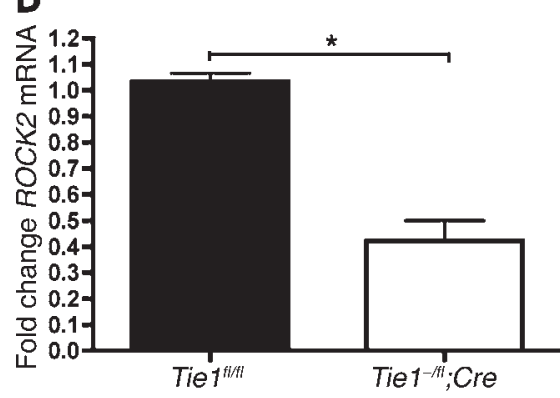

B

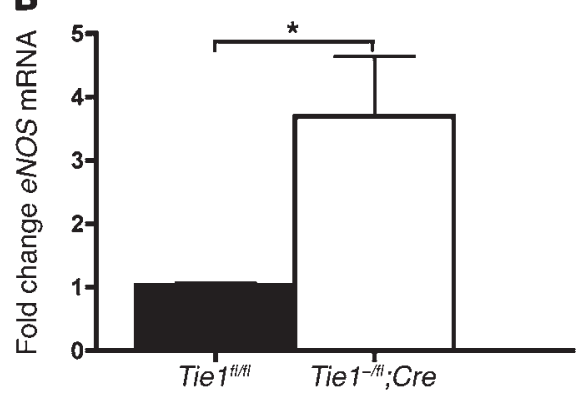

E

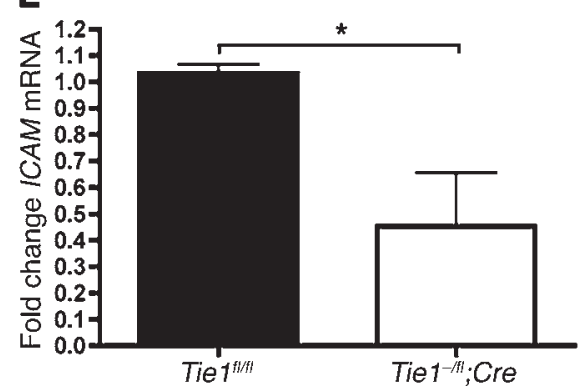

C

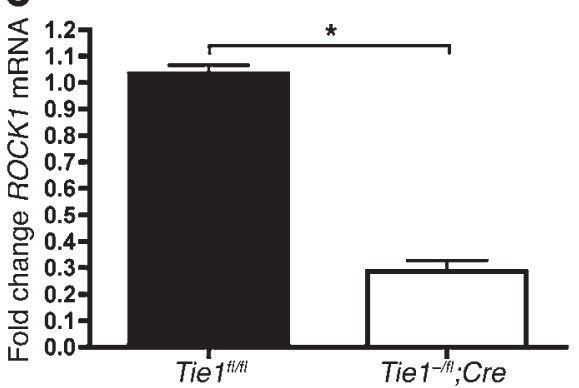

F

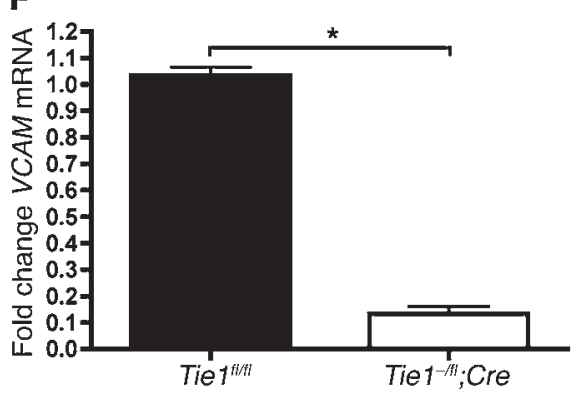

Figure 5

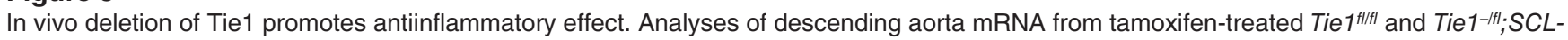
$E R^{T}$-Cre mice. Semiquantitative RT-PCR assay of $(\mathbf{A})$ Tie1 $(P<0.0001),(B)$ eNOS $(P<0.01),(\mathbf{C}) R 0 C K 1(P<0.001),(\mathbf{D}) R O C K 2(P<0.002)$, (E) ICAM $(P<0.05)$, and (F) VCAM $(P<0.001) . n=3$ per group. ${ }^{*} P<0.05$.

endothelial characteristics. The culture of MAECs is a technically challenging process, often resulting in low yields with poor propagation properties. We circumnavigated these problems through the generation of conditionally immortalized aortic endothelial cells from Tie $1^{f l / f l} ; S C L-E R^{T}$-Cre immorto mice and selecting with PECAM by flow-assisted cell sorting. Jat et al. first reported the derivation of conditionally immortalized cell lines from the $\mathrm{H}-2 \mathrm{~K}^{\mathrm{b}}$ tsA58 transgenic mouse (48); subsequently, several groups have successfully isolated a variety of cell lines from this mouse (49-51). In this model, the large TAg of a temperature-sensitive strain (tsA58) of the simian virus 40 (SV40) is fused with the major histocompatibility complex promoter $\mathrm{H}-2 \mathrm{~K}^{\mathrm{b}}$, which is active in a wide range of tissues and is induced by IFNs. The presence of the inducible tsA58 TAg allows for the extended propagation of MAECs under permissive conditions $\left(33^{\circ} \mathrm{C}\right.$, IFN- $\gamma$ ). MAECs transferred to normal culture conditions $\left(37^{\circ} \mathrm{C}\right)$ were confirmed to be endothelial by their characteristic cobblestone morphology, formation of microtubules on Matrigel, expression of CD31, and uptake of DiI-AcLDL. Additionally, MAECs aligned to the direction of laminar flow after only 24 hours (52). Our results indicate that immortalized MAECs display the characteristics germane to many primary endothelial cell lines.

We achieved $50 \%$ deletion of Tie 1 in vitro, concordant with in vivo tamoxifen-induced deletion in Tie $1^{f l / f l}$; SCL-ER $R^{T}$-Cre mice. We surmise that Cre expression under the SCL promoter may not be sufficient for extensive deletion of biallelic floxed Tie 1 and anticipate that enhanced deletion could be achieved by development of Tie $1^{-/ f l}$;SCL-ER ${ }^{T}$-Cre cells. Marron et al. previously reported cleavage of Tie 1 with phorbol ester or VEGF (35), while Chen-Konak and colleagues reported changes in levels of Tie1 intracellular fragment after brief alterations in shear stress (10). Upon administration of $4 \mathrm{OHT}$, we also noted a concomitant decrease in levels of cleaved
Tie 1 intracellular fragment. Whereas deletion of Tie 1 resulted in a 50\% reduction in full-length Tie1 receptor, the cleaved Tie1 fragment was decreased by $74 \%$. The significance of this observation is currently being explored.

Our in vitro experiments in MAECs showed that 24 hours of laminar flow at 20 dynes $/ \mathrm{cm}^{2}$ suppressed Tie 1 expression and increased eNOS activity, while oscillatory flow at 5 dynes $/ \mathrm{cm}^{2}$ for a similar duration augmented expression of Tie1. Using bovine aortic endothelial cells, Chen-Konak et al. found that brief in vitro application of shear stress at 10 dynes $/ \mathrm{cm}^{2}$ temporarily decreased Tie1, but expression levels returned to baseline after 2 hours (10). Therefore, our in vitro model recapitulated our in vivo data showing increased Tie1 expression at regions of disturbed flow. Stability of eNOS may be regulated by ROCK1 and ROCK2 $(53,54)$. We showed that genetic deletion of Tie 1 augmented eNOS activity in vivo and in vitro while downregulating the transcription of ROCK1 and ROCK2 in vivo. Hence, our data suggest that Tie1 may signal upstream of the ROCK-eNOS signaling pathway.

An octameric negative shear stress response element that downregulates Tie 1 expression has also been found (10). Shear stress response elements are targets of the NF- $\mathrm{\kappa B}$ transcription factor, which in turn can also be regulated by shear stress (55). Recent studies have shown that siRNA silencing of Tie 1 in vitro reduced expression of inflammatory markers (56), and overexpression studies demonstrated complementary findings (19), suggestive of a proinflammatory role for Tie1. We found that Tie1 deletion augmented shear stress-induced IkB $\alpha$ expression in vitro while decreasing expression of inflammatory biomarkers both in vivo and in vitro.

Finally, the effect of Tie1 deletion on the progression of atherosclerosis is unlikely to be exclusively related to decreases in Tie1mediated signaling. As mentioned above, Tie 1 and Tie 2 have been shown to interact physically $(21,23,24)$, but the in vivo biologi- 

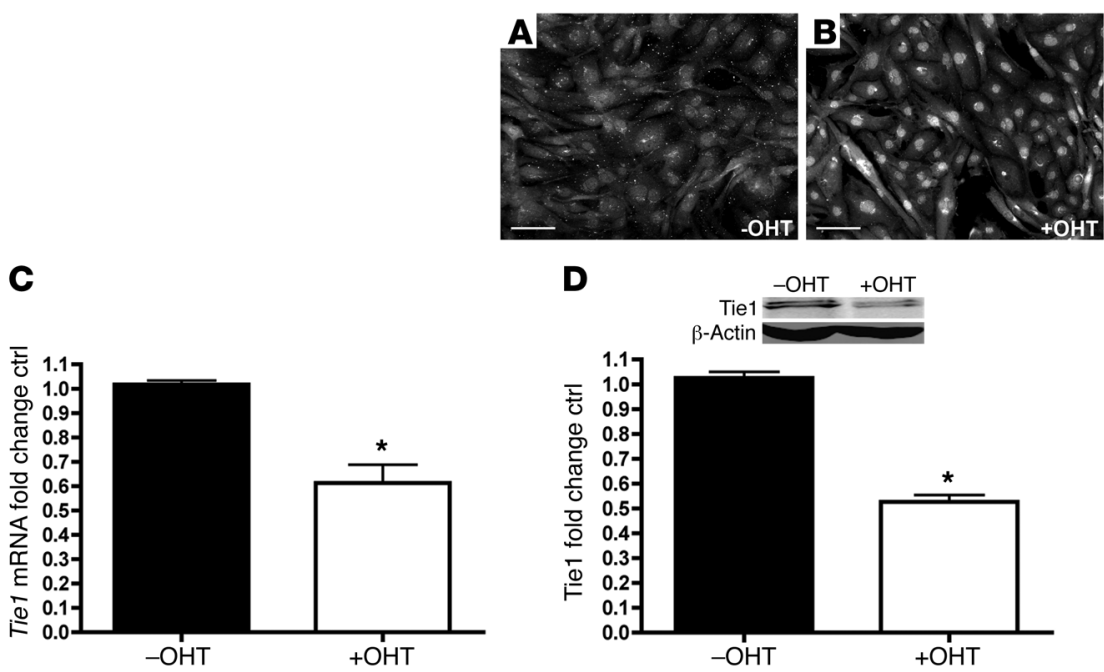

F
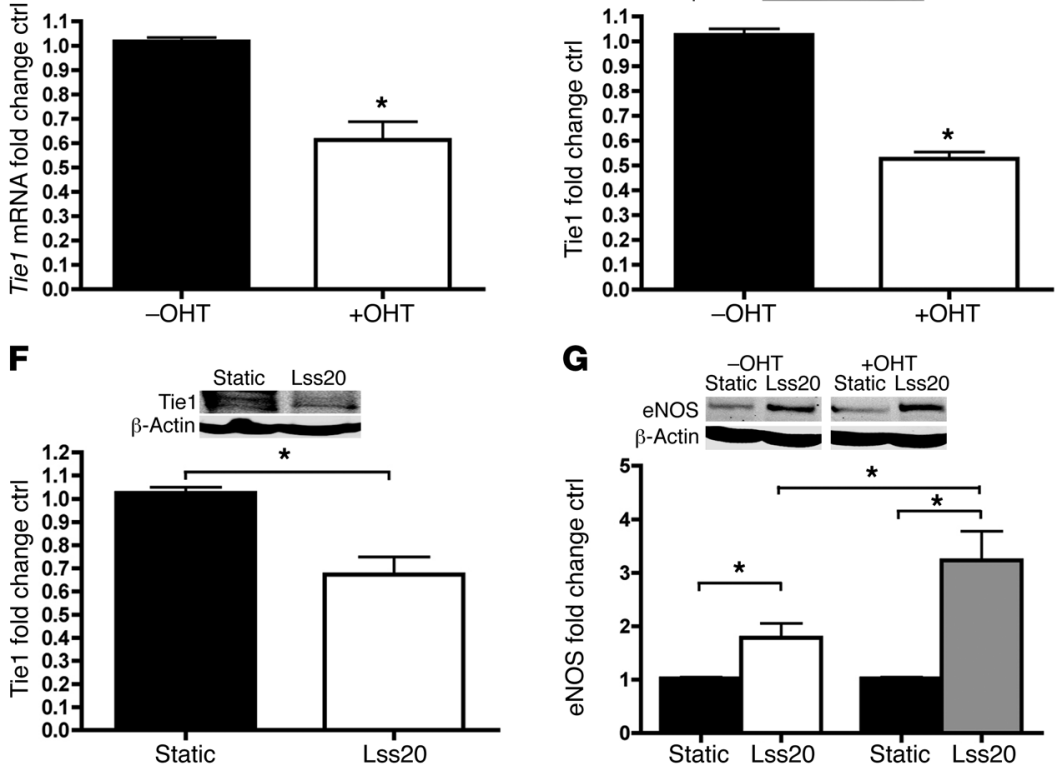

G

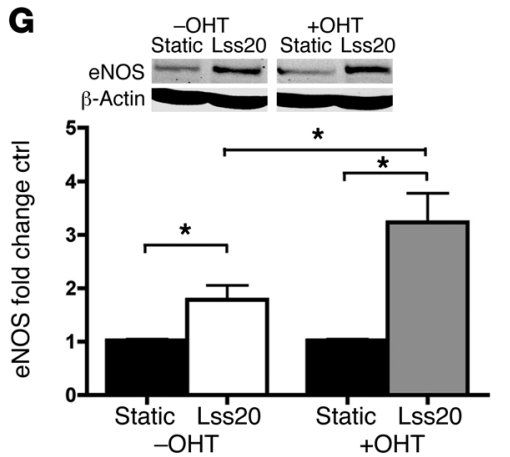

J

I
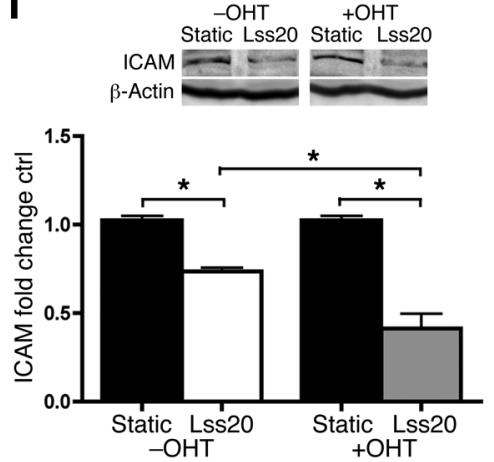

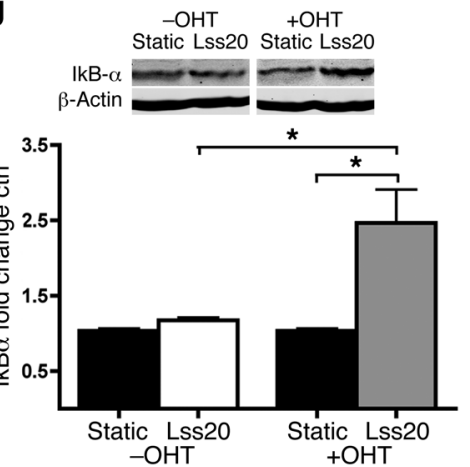

E

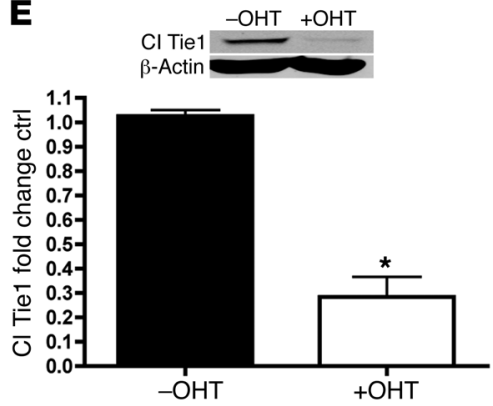

H

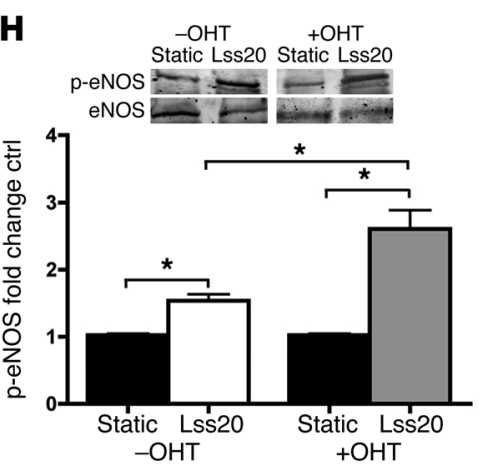

K
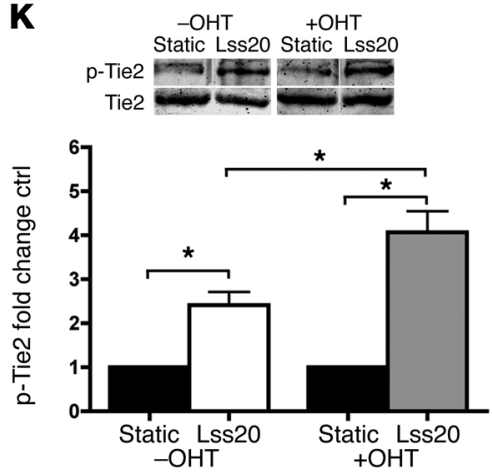

Figure 6

In vitro deletion of Tie1 and endothelial cell response to shear stress. (A-E) Treatment of Tie $1^{\text {fllflil }}$;CL-ER $R^{T}$-Cre MAECs with $4 \mathrm{OHT}$ activated Cre and reduced Tie1 expression. Representative immunofluorescent images showing Cre nuclear localization following 4OHT treatment (B) compared with untreated controls (A). Scale bars: $100 \mu \mathrm{m}$. (C) RT-PCR analysis of Tie1 mRNA levels. Western blot analyses of full-length protein levels (D) and cleaved Tie1 (Cl Tie1) 45-kDa endodomain levels (E). (F) Western blot analysis of full-length Tie1 receptor after 24 hours of shear stress showed that laminar flow at 20 dynes/cm² (Lss20) decreased Tie1 expression. (G-K) Western blot analyses of Tie1-deleted (i.e., 4OHTtreated) versus untreated control cells, comparing laminar shear-induced eNOS expression $(\mathbf{G})$, eNOS phosphorylation (H), ICAM expression (I), IkB $\alpha$ expression (J), and Tie2 phosphorylation (normalized to Tie2) (K). ${ }^{\star} P<0.05$.

cal relevance of these interactions has not been demonstrated. Attenuation of Tie1 has been shown to upregulate Tie2 phosphorylation (22), as has laminar flow (38). Our results showed that the combination of shear stress and Tie1 deletion augmented the increased phosphorylation of Tie2. Interestingly, increased Tie2 signaling has recently been associated with a decrease in atherosclerosis (57). A recent fluorescent resonance energy transfer-based proximity assay has documented Tie1-Tie2 complex formation at the cell surface and demonstrated that these interactions are inhibitory for Tie2 signaling (25). We did not observe a difference in the expression of either Ang1 or Ang2 in response to Tie 1 attenuation following 24 hours of in vitro laminar flow (data not shown). Therefore, it is likely that the increased phosphorylation of Tie2 under these conditions (Figure 6K) may be explained, at least in part, by the relief of inhibitory interactions normally imposed by association with Tie 1 . 
In summary, we found that Tie1 was expressed in specific regions experiencing atherogenic shear stress, and reduction of Tie 1 expression attenuated atherosclerosis progression in a shear stress-specific and dose-dependent manner. Our in vitro shear stress studies further suggest a proinflammatory role for Tie1, which we believe to be novel. This prophylactic alleviation of atherosclerosis burden by the reduction of Tie 1 expression and signaling points to Tie 1 as an attractive candidate for targeted therapeutic approaches.

\section{Methods}

Animal breeding and tamoxifen injections. Tie $1^{l z /+}$ mice were a gift from M.C. Puri (University of Toronto, Toronto, Ontario, Canada; ref. 12), and SCL-ER $R^{T}$-Cre mice were a gift from J.R. Gothert (University of Duisburg-Essen, Essen, Germany; ref. 33). Tie $1^{l z /+} ; A p o e^{-/-}$, Tie $1^{+/-} ; A p o e^{-/-}$, Tie $1^{f / f l} ; S C L-E R^{T}-C r e$, and Tie $1^{-/ f l}$; $S C L-E R^{T}$-Cre;Apoe ${ }^{-/-}$mice were bred in our laboratory. All mice used in this study were bred onto a pure C57BL/6 background and were maintained in microisolator cages on a rodent chow diet (Purina Mills Inc.) and autoclaved water ad libitum. Animal care and experimental procedures were approved by the Institutional Animal Care and Use Committee of Vanderbilt University. Tamoxifen injections were performed on 6-week-old mice. Intraperitoneal injections of $2 \mathrm{mg}$ tamoxifen (catalog no. T5648; Sigma-Aldrich) dissolved in $10 \%$ ethanol and $0.1 \mathrm{ml}$ sunflower oil (catalog no. S5007; Sigma-Aldrich) were administered once every 2 days ( 7 injections total).

Generation of Tie 1 mutant alleles. To generate Tie $1^{f l / f l}$ mice, a loxP site and a neomycin resistance cassette were introduced within the first intron of Tie1, and another loxP site was introduced just upstream of the minimal promoter region. This strategic placement of loxP sites would allow for excision of the Tie1 minimal promoter and exon 1 upon Cre activation (58).

Detection of $\beta$-galactosidase. Whole tissue was collected in HBSS; fixed in $0.2 \%$ glutaraldehyde, $2 \mathrm{mM} \mathrm{MgCl}$, and $5 \mathrm{mM}$ EGTA solution; and stained in $1 \mathrm{mg} / \mathrm{ml} \mathrm{X}$-gal, $2 \mathrm{mM} \mathrm{MgCl}$, $5 \mathrm{mM}$ EGTA, $0.01 \%$ deoxycholate, $0.02 \%$ NP-40, and $0.1 \mathrm{M}$ phosphate buffer ( $\mathrm{pH} 7.3$ ) solution overnight at $30^{\circ} \mathrm{C}$. The stained tissues were postfixed in $4 \%$ paraformaldehyde, cleared in a glycerol gradient, and photographed in $100 \%$ glycerol with a dissecting photomicroscope. Serial cryosections of aortic sinus adjacent to oil red $\mathrm{O}$-stained sections were stained as described above, postfixed with $4 \%$ paraformaldehyde, dehydrated in ethanol, cleared in xylene, counterstained with eosin, and mounted in permount.

Analysis of aortic lesions. The extent of atherosclerotic lesions was evaluated by 2 alternate methods: cross-sections of the aortic sinus and the whole aorta pinned out en face (59). Aortas were flushed through the left ventricle, and the entire aorta was dissected and pinned out for en face analysis as described previously (59). In addition, to quantify atherosclerotic lesions in the aortic sinus, the heart was embedded in OCT medium and frozen. $6-\mu \mathrm{m}$ cryosections of the aortic valve region was collected and processed for oil red O staining. Lesions in the aorta were analyzed using Imaging System KS 300 (Kontron Electonik GmbH). The mean atherosclerotic lesion area for each animal was determined by taking the average of 15 alternate sections for each mouse. To quantify atherosclerotic plaques in the aorta en face, the aorta was fixed in $4 \%$ paraformaldehyde and dissected free of fat. The aorta was stained in Sudan IV and analyzed using the Imaging System KS 300. Lesions in the distal aorta were evaluated in 2 ways. First, the percent lesion area for the whole aorta was calculated as total lesion area relative to total surface area. Second, lesions were assessed according to 3 regions: (a) lesser curvature of the aortic arch; (b) greater curvature of the aortic arch, including the brachiocephalic trunk, left common carotid artery, and left subclavian artery; and (c) descending aorta, including the thoracic, abdominal, and lumbar regions. For each region, the lesion area was calculated as a percentage of total aorta surface area.
Serum lipids and lipoprotein distribution analysis. Serum total cholesterol and triglyceride levels were determined on samples obtained from mice fasted for 4 hours as described previously (32). Fast performance liquid chromatography was performed on an HPLC system model 600 (Waters) using a Superose 6 column (Pharmacia).

Immunocytochemistry. The localization of mouse macrophages in the arterial lesions was examined by immunocytochemistry using $5-\mu \mathrm{m}$ cryosections of the aortic sinus fixed in acetone at $4^{\circ} \mathrm{C}$. The sections were immersed in PBS (pH 7.2), blocked in goat serum dilution (containing 4\% BSA and $2 \%$ goat serum), and incubated overnight at $4^{\circ} \mathrm{C}$ with monoclonal rat antibody MOMA-2 (Accurate Chemical \& Scientific Corp.). The sections were treated with goat biotinylated antibody rat IgG (BD Biosciences Pharmingen) for 45 minutes at $37^{\circ} \mathrm{C}$, then incubated with avidin-biotin complex labeled with alkaline phosphatase (Vector Laboratories). Enzyme was viewed with Fast Red TR/Naphthol AS-NX substrate (Sigma-Aldrich) and counterstained with hematoxylin. Nonimmune rabbit or rat serum was used in the place of primary antibody as a negative control. Photomicroscopy was performed on a Zeiss Axioskop microscope with PlanFLUAR objectives. Area of staining was normalized to total plaque area previously calculated for each mouse.

Shear stress-modifying cast. Casts were manufactured at the Vanderbilt Physics Machine Shop with medical grade polyetherketone (Invibio Inc.) using single lip micro cutters (provided by Alignment Tools Pte Ltd.). Casts with nonconstricting bores were used as controls. As described by Cheng et al., the tapered casts induce lowered shear stress $\left(10 \mathrm{~N} / \mathrm{m}^{2}\right)$ immediately upstream, increased shear stress inside the cast and oscillatory shear stress with vortex flow immediately downstream $(30,31)$. The tapered region increases shear stress from 10 to $25 \mathrm{~N} / \mathrm{m}^{2}$.

8 mice 12 weeks of age were assigned randomly to 2 groups. Shear stress in the right common carotid artery was altered by cast placement. Each animal was anesthetized with isoflurane, and the anterior cervical triangle was accessed by a sagittal anterior neck incision. Both halves of the cast were placed around the right common carotid artery and fixed with a suture. Wounds were closed, and the animals were allowed to recover. Animals with control and tapered casts were sacrificed 7 days after surgery.

Immunohistochemistry. Mouse carotid arteries were processed for wholemount immunostaining with VE-cadherin after $\beta$-gal staining. Tissue samples were blocked in $10 \%$ goat serum at room temperature for 30 minutes and incubated with rabbit antibody to VE-cadherin (catalog no. 160840; Cayman Chemical) diluted in blocking solution at $4^{\circ} \mathrm{C}$ overnight.

Sections were treated with goat biotinylated antibody to rabbit IgG (BD Biosciences - Pharmingen) for 45 minutes at $37^{\circ} \mathrm{C}$. Then, sections were incubated with avidin-biotin complex labeled with peroxidase (Vector Laboratories). Enzyme was viewed with 3,3'-diaminobenzidine (DAB) substrate (Sigma-Aldrich).

Protein isolation and Western blotting. Tissue samples or cells were lysed on ice using a lysis buffer (50 mM Tris, $50 \mathrm{mM} \mathrm{NaCl}, 1 \%$ Triton X-100, $1 \mathrm{mM}$ EGTA, $1 \mathrm{mM} \mathrm{Na}_{3} \mathrm{VO}_{4}, 5 \mathrm{mM} \mathrm{NaF}$, and $1 \times \beta$-glycerophosphate) supplemented with complete protease inhibitor cocktail (Roche). After centrifugation, the supernatant was collected. Protein concentrations were determined with Protein Assay Reagent (BioRad Laboratories). The nuclear pellet was rinsed 3 times in lysis buffer and incubated at $100^{\circ} \mathrm{C}$ with $2 \times$ sample buffer to extract nuclear proteins. Lysates were resolved by SDS-PAGE electrophoresis and transferred onto Hybond ECL nitrocellulose membranes (GE Healthcare). Blots were blocked with 5\% nonfat milk and probed with rabbit antibodies to Tie1 (catalog no. sc342 ; Santa Cruz), NOS3 (catalog no. sc654 ; Santa Cruz), phospho-NOS3 (catalog no. sc12972 ; Santa Cruz), Tie2 (catalog no. sc342 ; Santa Cruz), ICAM (catalog no. sc1511; Santa Cruz), IkB $\alpha$ (catalog no. sc1643; Santa Cruz), phospho-Tie2 (catalog no. AF2720; R\&D Systems), and mouse antibody to 
$\beta$-actin (catalog no. A5316; Sigma-Aldrich) overnight at $4^{\circ} \mathrm{C}$. After washing with $0.1 \%$ Tween-20-supplemented PBS (PBST), blots were incubated with secondary antibodies IRDye $800 \mathrm{CW}$ goat anti-rabbit IgG and IRDye $680 \mathrm{CW}$ goat anti-mouse IgG for 1 hour at room temperature with gentle agitation. Blots were washed and scanned on the Odyssey Infrared Imaging System (LI-COR Biosciences) and densitometry analyses were performed using Odyssey Software.

MAEC isolation. The immorto mouse is a transgenic mouse generated by the introduction of thermolabile SV40 TAg, tsA58 (48). In this model, the SV40 large TAg of temperature-sensitive strain tsA58 is fused with the major histocompatibility complex promoter $\mathrm{H}-2 \mathrm{~K}^{\mathrm{b}}$. Expression of the promoter and the large TAg protein is only evident when immorto mousederived cells are cultured at a permissive temperature $\left(33^{\circ} \mathrm{C}\right)$. The addition of IFN- $\gamma$ was also used to further enhance promoter activity (48). A 4- to 8 -week-old immorto mouse was anesthetized with isoflurane and sacrificed by cervical dislocation. The lumbar aorta was punctured, and $5 \mathrm{ml}$ of HBSS was perfused through the left ventricle to flush out blood. The heart, lung, and aorta bloc was excised and transferred to a dish containing HBSS and antibiotics. The heart and lungs were removed. The rest of the aorta was incubated at $37^{\circ} \mathrm{C}$ for 15 minutes with filtered $10 \mathrm{mg} / \mathrm{ml}$ collagenase type II (Worthington Chemicals) and $1 \times$ antibiotics dissolved in dispase (Roche). The adventitia was gently removed, and the remaining intima layer comprising the endothelium and internal elastic lamina was cut open longitudinally and incubated at $37^{\circ} \mathrm{C}$ for 30 minutes in filtered $20 \mathrm{mg} / \mathrm{ml}$ collagenase type II solution and $1 \times$ antibiotics dissolved in dispase. The aorta was dissociated by pipetting several times in the dissolving solution and filtered through a $100 \mu \mathrm{m}$ sterile cell strainer (Fisher Scientific). Culture media (MCDB 131 [Gibco, Invitrogen], 10\% FBS [Hyclone], $10 \mathrm{U} / \mathrm{ml}$ heparin [Sigma-Aldrich], $2.75 \mathrm{nM}$ hydrocortisone [Sigma-Aldrich], 0.2\% bovine brain extract [Hammond Celltech], $10 \mathrm{U} / \mathrm{ml}$ recombinant murine IFN $-\gamma$ [Peprotech], and $1 \times$ antibiotics [Gibco, Invitrogen]) was added to the cell suspension and centrifuged at $375 \mathrm{~g}$ for 10 minutes. The cell mixture was then plated onto a fibronectin coated culture dish and propagated at $33^{\circ} \mathrm{C}$ in a mixture of $5 \%$ carbon dioxide and $95 \%$ oxygen. MAECs were

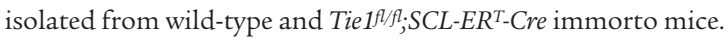

Flow-assisted cell sorting. MAECs were released from the plate by incubating with Accutase (Invitrogen) for 10 minutes at $37^{\circ} \mathrm{C}$. Cells were collected by centrifugation at $375 \mathrm{~g}$ for 10 minutes at $4^{\circ} \mathrm{C}$ and resuspended in HBSS (supplemented with $1 \% \mathrm{FBS}$ and $1 \times$ antibiotics). The cells were then incubated with APC-conjugated CD31 (catalog no. 551262; BD Biosciences) at $1 \mathrm{mg} / 1 \times 10^{6}$ cells for 30 minutes on ice with occasional agitation. MAECs were washed 3 times in HBSS and filtered through a $40-\mu \mathrm{m}$ cell strainer (Fisher Scientific). Propidium iodide (Invitrogen) was added at 1:1,000 dilution prior to sorting. $\mathrm{CD} 31^{+}$cells were collected in culture media, centrifuged, and plated onto collagen-coated (Rat tail collagen type I; BD Biosciences) dishes.

MAEC characterization. MAECs were rinsed with PBS, briefly fixed with methanol at $-20^{\circ} \mathrm{C}$, and blocked with $10 \%$ normal goat serum (Jackson ImmunoResearch) for 1 hour at room temperature. Immunostaining was performed at $4{ }^{\circ} \mathrm{C}$ overnight with either CD31 (catalog no. 553370; BD Biosciences) or VE-cadherin (catalog no. 160840; Cayman Chemical) and counterstaining with goat anti-rat Alexa Fluor 488 (BD Biosciences) or goat anti-rabbit Alexa Fluor 488. MAECs were also cultured on Matrigelcoated (BD Biosciences) dishes overnight and observed for network formation. DiI-AcLDL (Biomedical Technologies) was added to the media at $10 \mu \mathrm{g} / \mathrm{ml}$ for up to 6 hours and washed to observe uptake in MAECs.

Induction of Cre activation by $4 \mathrm{OHT}$ and immunocytochemistry. MAECs from Tie $1^{\text {flffl }}$;SCL-ER $R^{T}$-Cre mice were cultured at $37^{\circ} \mathrm{C}$ in complete media (as described above) without IFN- $\gamma$ and treated with $5 \mu \mathrm{M} 4 \mathrm{OHT}$ (SigmaAldrich) every 2 days for 6 days. To ascertain ER ${ }^{\mathrm{T}}$-Cre nuclear localization,
4OHT-treated cells were rinsed once with HBSS, fixed with cold $100 \%$ methanol for 3 minutes, and rinsed twice with HBSS. Cells were blocked with $5 \%$ goat serum, incubated overnight at $4{ }^{\circ} \mathrm{C}$ with Cre antibody (Abcam, AB24608), rinsed, and immunostained with Alexa Fluor 488-conjugated goat anti-rabbit secondary antibody (BD Biosciences).

Shear stress experiments. Shear stress experiments were performed using a custom cone-and-plate shear stress viscometer design. An inverted servo motor (ElectroCraft) was attached to a plexiglass cone with $0.5^{\circ}$ angle. A Motomatic II motor controller (Reliance Electric, ElectroCraft) regulated velocity in laminar flow, and a digital function generator (Instek) was used to produce a sinusoidal waveform modulating oscillatory flow. A digital oscilloscope (Tektronix) was used in parallel to monitor the output magnitude and waveform. The servomotor and cone were lowered onto the culture dish by a step-controlled base stand. Laminar shear was attained with unidirectional motion of the cone, while oscillatory shear was achieved by bidirectional motion at 5 dynes $/ \mathrm{cm}^{2}$. Shear stress experiments were performed for 24 hours in complete media in a sterile, $5 \% \mathrm{CO}_{2}$ incubator at $37^{\circ} \mathrm{C}$.

$R N A$ extraction and real-time RT-PCR. RNA from tissue or cells was isolated using TriReagent (Molecular Research Center), and SuperScript III First-Strand System (Invitrogen) was used to synthesize first-strand cDNA. Quantitative real-time RT-PCR was performed using iQ SYBR Green Supermix (BioRad) on the iQ5 Real Time PCR Detection System (BioRad). Experiments were performed in triplicate using glyceraldehyde3-phosphate dehydrogenase as the housekeeping gene to normalize the data. The relative change in gene expression was determined using the criti-

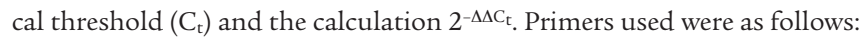
Tie1, 5'-GTGCCACCATTTTGACACTG-3' and 5'-CAGGCACAGCAGGTTGTAGA-3'; glyceraldehyde-3-phosphate dehydrogenase, 5'-CACTGGCATGGCCTTCCGTG-3' and 5'-AGGAAATGAGCTTGACAAAG-3; VCAM, 5'-AAGAGAACCCAGGTGGAGGT-3' and 5'-GGGGCAACGTTGACATAAAG-3'; ICAM, 5'-GAAGGTGGTTCTTCTGAGCG-3' and 5'-AGGCATGGCACACGTATGTA-3'; NOS3, 5'-TGAAGATCTCTGCCTCACTCATG-3' and 5'-AGTCTCAGAGCCATACCAGAATGGTT-3'.

Statistics. All statistical differences in this study were determined by a 2-tailed, unpaired Student's $t$ test with 95\% confidence intervals, using Prism 4.0 software (Graphpad Inc.). Statistical significance was accepted for $P$ values less than 0.05 . Graphical data representations are presented as mean $\pm \mathrm{SEM}$.

\section{Acknowledgments}

We thank Youmin Zhang for excellent technical expertise. We also thank Christopher Brown for invaluable support and experimental advice. K.V. Woo was supported by the Vanderbilt Medical Scientist Training Program (NIH grant T32 GM00734731) and an American Heart Association Predoctoral Fellowship. H.S. Baldwin and K.V. Woo were supported by NIH grants RL1 HL0952551 and MOD FY07-513 (both to H.S. Baldwin). S. Fazio was supported by NIH R01 grants 65709 and 57986. M.F. Linton was supported by NIH grants HL065405 and HL086988. This work was also supported by NIH grant DK59637 (Lipid, Lipoprotein, and Atherosclerosis Core of the Vanderbilt Mouse Metabolic Phenotype Centers).

Received for publication July 29, 2010, and accepted in revised form January 12, 2011.

Address correspondence to: H. Scott Baldwin, 9435-A MRB IV, Vanderbilt University Medical Center, Nashville, Tennessee 372320493, USA. Phone: 615.322.2703; Fax: 615.322.6541; E-mail: scott. baldwin@vanderbilt.edu. 
1. Cornhill JF, Roach MR. A quantitative study of the localization of atherosclerotic lesions in the rabbit aorta. Atherosclerosis. 1976;23(3):489-501.

2. Davies PF, Polacek DC, Handen JS, Helmke BP, DePaola N. A spatial approach to transcriptional profiling: mechanotransduction and the focal origin of atherosclerosis. Trends Biotechnol. 1999;17(9):347-351.

3. Gimbrone MA Jr, Nagel T, Topper JN. Biomechanical activation: an emerging paradigm in endothelial adhesion biology. J Clin Invest. 1997; 100(11 suppl):S61-S65.

4. Asakura T, Karino T. Flow patterns and spatial distribution of atherosclerotic lesions in human coronary arteries. Circ Res. 1990;66(4):1045-1066.

5. Li YS, Haga JH, Chien S. Molecular basis of the effects of shear stress on vascular endothelial cells. J Biomech. 2005;38(10):1949-1971.

6. Chien S. Role of shear stress direction in endothelial mechanotransduction. Mol Cell Biomech. 2008;5(1):1-8

7. Tricot O, Mallat Z, Heymes C, Belmin J, Leseche G, Tedgui A. Relation between endothelial cell apoptosis and blood flow direction in human atherosclerotic plaques. Circulation. 2000;101(21):2450-2453.

8 . Slager CJ, et al. The role of shear stress in the generation of rupture-prone vulnerable plaques. Nat Clin Pract Cardiovasc Med. 2005;2(8):401-407.

9. Porat RM, et al. Specific induction of tie 1 promoter by disturbed flow in atherosclerosis-prone vascular niches and flow-obstructing pathologies. Circ Res. 2004;94(3):394-401.

10. Chen-Konak L, et al. Transcriptional and posttranslation regulation of the Tie 1 receptor by fluid shear stress changes in vascular endothelial cells. FASEB J. 2003;17(14):2121-2123.

11. Partanen J, et al. A novel endothelial cell surface receptor tyrosine kinase with extracellular epidermal growth factor homology domains. Mol Cell Biol. 1992;12(4):1698-1707.

12. Puri MC, Rossant J, Alitalo K, Bernstein A, Partanen $\mathrm{J}$. The receptor tyrosine kinase TIE is required for integrity and survival of vascular endothelial cells. EMBO J. 1995;14(23):5884-5891.

13. Sato TN, et al. Distinct roles of the receptor tyrosine kinases Tie-1 and Tie-2 in blood vessel formation. Nature. 1995;376(6535):70-74.

14. Antonescu CR, et al. KDR activating mutations in human angiosarcomas are sensitive to specific kinase inhibitors. Cancer Res. 2009;69(18):7175-7179.

15. Kaipainen A, et al. Enhanced expression of the tie receptor tyrosine kinase mesenger RNA in the vascular endothelium of metastatic melanomas. Cancer Res. 1994;54(24):6571-6577.

16. Korhonen J, et al. Enhanced expression of the tie receptor tyrosine kinase in endothelial cells during neovascularization. Blood. 1992;80(10):2548-2555.

17. Shahrara S, Volin MV, Connors MA, Haines GK, Koch AE. Differential expression of the angiogenic Tie receptor family in arthritic and normal synovial tissue. Arthritis Res. 2002;4(3):201-208.

18. Malik NM, et al. Regulation of the AngiopoietinTie ligand-receptor system with a novel splice variant of Tie 1 reduces the severity of murine arthritis. Rheumatology (Oxford). 2010;49(10):1828-1839.

19. Chan B, Yuan HT, Ananth Karumanchi S, Sukhatme VP. Receptor tyrosine kinase Tie-1 overexpression in endothelial cells upregulates adhesion molecules. Biochem Biophys Res Commun. 2008; 371(3):475-479.

20. Marron MB, Hughes DP, Edge MD, Forder CL, Brindle NP. Evidence for heterotypic interaction between the receptor tyrosine kinases TIE-1 and TIE-2. J Biol Chem. 2000;275(50):39741-39746.

21. Saharinen P, et al. Multiple angiopoietin recombi- nant proteins activate the Tie 1 receptor tyrosine kinase and promote its interaction with Tie2.J Cell Biol. 2005;169(2):239-243.

22. Yuan HT, et al. Activation of the orphan endothelial receptor Tie1 modifies Tie2-mediated intracellular signaling and cell survival. FASEB J. 2007;21(12):3171-3183

23. Saharinen P, et al. Angiopoietins assemble distinct Tie2 signalling complexes in endothelial cell-cell and cell-matrix contacts. Nat Cell Biol. 2008;10(5):527-537.

24. Kim KL, et al. Interaction between Tie receptors modulates angiogenic activity of angiopoietin 2 in endothelial progenitor cells. Cardiovasc Res. 2006; 72(3):394-402.

25. Seegar TC, et al. Tie1-Tie2 interactions mediate functional differences between angiopoietin ligands. Mol Cell. 2010;37(5):643-655.

26. Marron MB, Hughes DP, McCarthy MJ, Beaumont ER, Brindle NP. Tie-1 receptor tyrosine kinase endodomain interaction with SHP2: potential signalling mechanisms and roles in angiogenesis. $A d v$ Exp Med Biol. 2000;476:35-46.

27. Taichman DB, Schachtner SK, Li Y, Puri MC, Bernstein A, Scott Baldwin H. A unique pattern of Tie1 expression in the developing murine lung. Exp Lung Res. 2003;29(2):113-122.

28. Peacock JA. An in vitro study of the onset of turbulence in the sinus of Valsalva. Circ Res. 1990; $67(2): 448-460$

29. Simmons CA, Grant GR, Manduchi E, Davies PF. Spatial heterogeneity of endothelial phenotypes correlates with side-specific vulnerability to calcification in normal porcine aortic valves. Circ Res. 2005; 96(7):792-799.

30. Cheng $C$, et al. Shear stress affects the intracellular distribution of eNOS: direct demonstration by a novel in vivo technique. Blood. 2005;106(12):3691-3698.

31. Cheng $\mathrm{C}$, et al. Atherosclerotic lesion size and vulnerability are determined by patterns of fluid shear stress. Circulation. 2006;113(23):2744-2753.

32. Fazio $S$, et al. Increased atherosclerosis in mice reconstituted with apolipoprotein E null macrophages. Proc Natl Acad Sci U S A. 1997;94(9):4647-4652.

33. Gothert JR, et al. Genetically tagging endothelial cells in vivo: bone marrow-derived cells do not contribute to tumor endothelium. Blood. 2004;104(6):1769-1777.

34. Reckless J, Metcalfe JC, Grainger DJ. Tamoxifen decreases cholesterol sevenfold and abolishes lipid lesion development in apolipoprotein E knockout mice. Circulation. 1997;95(6):1542-1548.

35. Marron MB, et al. Regulated proteolytic processing of Tie 1 modulates ligand responsiveness of the receptor-tyrosine kinase Tie2. J Biol Chem. 2007; 282(42):30509-30517.

36. McCarthy MJ, Burrows R, Bell SC, Christie G, Bell $\mathrm{PR}$, Brindle NP. Potential roles of metalloprotease mediated ectodomain cleavage in signaling by the endothelial receptor tyrosine kinase Tie-1. Lab Invest. 1999;79(7):889-895.

37. Kuchan MJ, Frangos JA. Role of calcium and calmodulin in flow-induced nitric oxide production in endothelial cells. Am J Physiol. 1994; 266(3 pt 1):C628-636

38. Lee HJ, Koh GY. Shear stress activates Tie2 receptor tyrosine kinase in human endothelial cells. Biochem Biophys Res Commun. 2003;304(2):399-404.

39. Suo J, Ferrara DE, Sorescu D, Guldberg RE, Taylor WR, Giddens DP. Hemodynamic shear stresses in mouse aortas: implications for atherogenesis. Arterioscler Thromb Vasc Biol. 2007;27(2):346-351.

40. Cheng C, et al. Large variations in absolute wall shear stress levels within one species and between species. Atherosclerosis. 2007;195(2):225-235.
41. Greve JM, et al. Allometric scaling of wall shear stress from mice to humans: quantification using cine phase-contrast MRI and computational fluid dynamics. Am J Physiol Heart Circ Physiol. 2006;291(4):H1700-H1708

42. Patan S. TIE1 and TIE2 receptor tyrosine kinases inversely regulate embryonic angiogenesis by the mechanism of intussusceptive microvascular growth. Microvasc Res. 1998;56(1):1-21.

43. Kontos CD, Cha EH, York JD, Peters KG. The endothelial receptor tyrosine kinase Tie 1 activates phosphatidylinositol 3-kinase and Akt to inhibit apoptosis. Mol Cell Biol. 2002;22(6):1704-1713.

44. Eklund L, Olsen BR. Tie receptors and their angiopoietin ligands are context-dependent regulators of vascular remodeling. Exp Cell Res. 2006;312(5):630-641.

45. Goel R, et al. Site-specific effects of PECAM-1 on atherosclerosis in LDL receptor-deficient mice. Arterioscler Thromb Vasc Biol. 2008;28(11):1996-2002.

46. Harry BL, et al. Endothelial cell PECAM-1 promotes atherosclerotic lesions in areas of disturbed flow in ApoE-deficient mice. Arterioscler Thromb Vasc Biol. 2008;28(11):2003-2008.

47. Butcher JT, et al. Transcriptional profiles of valvular and vascular endothelial cells reveal phenotypic differences: influence of shear stress. Arterioscler Thromb Vasc Biol. 2006;26(1):69-77.

48. Jat PS, et al. Direct derivation of conditionally immortal cell lines from an $\mathrm{H}-2 \mathrm{~Kb}-\mathrm{ts} A 58$ transgenic mouse. Proc Natl Acad Sci U S A. 1991;88(12):5096-5100.

49. Langley RR, Ramirez KM, Tsan RZ, Van Arsdall M, Nilsson MB, Fidler IJ. Tissue-specific microvascular endothelial cell lines from $\mathrm{H}-2 \mathrm{~K}(\mathrm{~b})$-tsA58 mice for studies of angiogenesis and metastasis. Cancer Res. 2003;63(11):2971-2976.

50. Lidington EA, Rao RM, Marelli-Berg FM, Jat PS, Haskard DO, Mason JC. Conditional immortalization of growth factor-responsive cardiac endothelial cells from $\mathrm{H}-2 \mathrm{~K}(\mathrm{~b})$-tsA58 mice. Am J Physiol Cell Physiol. 2002;282(1):C67-74.

51. Whitehead RH, VanEeden PE, Noble MD, Ataliotis P, Jat PS. Establishment of conditionally immortalized epithelial cell lines from both colon and small intestine of adult $\mathrm{H}-2 \mathrm{~Kb}-\mathrm{tsA} 58$ transgenic mice. Proc Natl Acad Sci U S A. 1993;90(2):587-591.

52. Remuzzi A, Dewey CF Jr, Davies PF, Gimbrone MA Jr. Orientation of endothelial cells in shear fields in vitro. Biorheology. 1984;21(4):617-630.

53. Noma K, Oyama N, Liao JK. Physiological role of ROCKs in the cardiovascular system. Am J Physiol Cell Physiol. 2006;290(3):C661-C668.

54. Zhou Q, Liao JK. Rho kinase: an important mediator of atherosclerosis and vascular disease. Curr Pharm Des. 2009;15(27):3108-3115.

55. Gimbrone MA Jr, et al. Special communicationthe critical role of mechanical forces in blood vessel development, physiology and pathology. J Vasc Surg. 1999;29(6):1104-1151.

56. Chan B, Sukhatme VP. Suppression of Tie-1 in endothelial cells in vitro induces a change in the genome-wide expression profile reflecting an inflammatory function. FEBS Lett. 2009; 583(6):1023-1028.

57. Ahmed A, et al. Angiopoietin-2 confers Atheroprotection in apoE $-/-$ mice by inhibiting LDL oxidation via nitric oxide. Circ Res. 2009;104(12):1333-1336.

58. Qu X, Tompkins K, Batts LE, Puri M, Baldwin S. Abnormal embryonic lymphatic vessel development in Tie1 hypomorphic mice. Development. 2010; 137(8):1285-1295.

59. Babaev VR, et al. Conditional knockout of macrophage PPARgamma increases atherosclerosis in C57BL/ 6 and low-density lipoprotein receptordeficient mice. Arterioscler Thromb Vasc Biol. 2005; 25(8):1647-1653. 